\title{
Distinct $\beta$ Band Oscillatory Networks Subserving Motor and Cognitive Control during Gait Adaptation
}

\author{
Johanna Wagner, ${ }^{1,2}$ @Scott Makeig, ${ }^{2}$ Mateusz Gola, ${ }^{2,3}$ Christa Neuper, ${ }^{1,4}$ and Gernot Müller-Putz ${ }^{1}$ \\ ${ }^{1}$ Laboratory of Brain-Computer Interfaces, Institute for Knowledge Discovery, Graz University of Technology, 8010 Graz, Austria, ${ }^{2}$ Swartz Center for \\ Computational Neuroscience, Institute for Neural Computation, University of California-San Diego, La Jolla, California 92093-0559, ${ }^{3}$ Institute of \\ Psychology, Polish Academy of Science, Warsaw 00-378, Poland, and ${ }^{4}$ Department of Psychology, University of Graz, 8010 Graz, Austria
}

Everyday locomotion and obstacle avoidance requires effective gait adaptation in response to sensory cues. Many studies have shown that efficient motor actions are associated with $\mu$ rhythm $(8-13 \mathrm{~Hz})$ and $\beta$ band $(13-35 \mathrm{~Hz})$ local field desynchronizations in sensorimotor and parietal cortex, whereas a number of cognitive task studies have reported higher behavioral accuracy to be associated with increases in $\beta$ band power in prefrontal and sensory cortex. How these two distinct patterns of $\beta$ band oscillations interplay during gait adaptation, however, has not been established. Here we recorded 108 channel EEG activity from 18 participants (10 males, 22-35 years old) attempting to walk on a treadmill in synchrony with a series of pacing cue tones, and quickly adapting their step rate and length to sudden shifts in pacing cue tempo. Independent component analysis parsed each participant's EEG data into maximally independent component (IC) source processes, which were then grouped across participants into distinct spatial/spectral clusters. Following cue tempo shifts, mean $\beta$ band power was suppressed for IC sources in central midline and parietal regions, whereas mean $\beta$ band power increased in IC sources in or near medial prefrontal and dorsolateral prefrontal cortex. In the right dorsolateral prefrontal cortex IC cluster, the $\beta$ band power increase was stronger during (more effortful) step shortening than during step lengthening. These results thus show that two distinct patterns of $\beta$ band activity modulation accompany gait adaptations: one likely serving movement initiation and execution; and the other, motor control and inhibition.

Key words: $\beta$ band oscillations; EEG; gait adaptation; independent component analysis; motor inhibition; rhythmic auditory cueing

\section{Significance Statement}

Understanding brain dynamics supporting gait adaptation is crucial for understanding motor deficits in walking, such as those associated with aging, stroke, and Parkinson's. Only a few electromagnetic brain imaging studies have examined neural correlates of human upright walking. Here, application of independent component analysis to EEG data recorded during treadmill walking allowed us to uncover two distinct $\beta$ band oscillatory cortical networks that are active during gait adaptation to shifts in the tempo of an auditory pacing cue: $(8-13 \mathrm{~Hz}) \mu$ rhythm and $(13-35 \mathrm{~Hz}) \beta$ band power decreases in central and parietal cortex and (14-20 $\mathrm{Hz}) \beta$ band power increases in frontal brain areas. These results provide a fuller framework for electrophysiological studies of cortical gait control and its disorders.

\section{Introduction}

Impaired gait adaptability (i.e., a reduced ability to change walking speed or direction as required) (Den Otter et al., 2005; Hofstad et al., 2006) produces a reduced ability to avoid obstacles and an increased

\footnotetext{
Received Sept. 23, 2015; revised Dec. 26, 2015; accepted Jan. 11, 2016.

Author contributions: J.W. designed research; J.W., M.G., C.N, and G.M.-P. performed research; J.W. and S.M., analyzed data; J.W., S.M, and M.G. wrote the paper.

This work was supported by Future Labs Reloaded 2013 of the Faculty of Computer Science at the Graz University of Technology, Austria, OeAD (Austrian Agency for International Mobility) Marietta Blau Grant to J.W., the BMWF (Austrian Federal Ministry of Science and Research), Polish Ministry of Science Mobility Plus Grant 1057/MOB/ 2013/0 to M.G., and a gift to University of California-San Diego by the Swartz Foundation (Old Field, NY). We thank Dr. Teodoro Solis-Escalante for programming the auditory paradigm; and Daniel Hackhofer and Laura Schulz for assistance during the experiments.

The authors declare no competing financial interests.
}

risk of falling in affected individuals, including many stroke and Parkinson's patients (Weerdesteyn et al., 2006). Rhythmic auditory cues have been widely used in gait rehabilitation (Thaut and Abiru, 2010). Use of an auditory pacing stimulus stream, including infrequent tempo shifts, has been recommended to identify deficits and train improvements in gait adaptation in stroke patients (Roerdink et al., 2009, 2007). Unfortunately, because of the ill effects of body movements on brain imaging data, the precise temporal brain dy-

Correspondence should be addressed to Dr. Johanna Wagner, Laboratory of Brain-Computer Interfaces, Institute for Knowledge Discovery, Graz University of Technology, Stremayrgasse 16, 8010 Graz, Austria. E-mail: joa.wagn@gmail.com.

DOI:10.1523/JNEUROSCI.3543-15.2016

Copyright $\odot 2016$ the authors $\quad 0270-6474 / 16 / 362212-15 \$ 15.00 / 0$ 
namics of step adaptation remain largely unexplored by neuroimaging studies. Recent signal processing advances, however, allow study of source-resolved EEG dynamics during walking (Gwin et al., 2010, 2011; Gramann et al., 2011; Seeber et al., 2015) and other actions, an approach termed Mobile Brain/Body Imaging by Makeig et al. (2009). Adopting this approach, in several previous studies, we showed that specific gait phases are represented in power amplitude modulations in the lower $(24-40 \mathrm{~Hz}$ ) (Wagner et al., 2012, 2014; Seeber et al., 2014) and upper (70-90 Hz) (Seeber et al., 2015) $\gamma$ band in central midline areas. Other studies have shown lateralized modulations at scalp electrode channels C3 and C4 (Cheron et al., 2012) and in source-resolved (Gwin et al., 2011) power relative to the gait cycle.

We have also reported $\mu$ rhythm and $\beta$-band power decreases (desynchronizations) over central sensorimotor and parietal areas during active walking relative to standing or passive walking (i.e., when participants' legs are moved by a robot) (Wagner et al., 2012; Seeber et al., 2014) and during step adaptation to interactive visual feedback in a virtual environment (Wagner et al., 2014). $\mu$ and $\beta$ band power in the motor system decrease during the preparation and voluntary execution of movements (Jasper and Penfield, 1949; Pfurtscheller and Berghold, 1989; Pfurtscheller and Lopes da Silva, 1999), whereas $\beta$ band power increases in scalp EEG data have been related to movement suppression (Gilbertson et al., 2005; Androulidakis et al., 2007; Zhang et al., 2008; Pogosyan et al., 2009; Joundi et al., 2012; Solis-Escalante et al., 2012).

Electrophysiological studies suggest that $\beta$ band oscillations may also index top-down signaling. For example, visual top-down attention and behavioral rule switching are related to oscillatory synchronization of $\beta$-band local field potentials in monkeys' prefrontal cortex (PFC) and parietal cortex (Buschman et al., 2007, 2012). PFC affects top-down control by sending information about goals and appropriate actions to other brain areas (Miller and Cohen, 2001). Swann et al. (2009) reported that an electrocortical $\beta$ band power increase in PFC during motor inhibition preceded $\mu$ and $\beta$ band power decreases in motor cortex, whereas in older subjects $\beta$ band activity increases may have a compensatory effect (Geerligs et al., 2012; Gola et al., 2012, 2013).

Recent studies of gait adaptation using EEG showed increased event-related potential (ERP) (Haefeli et al., 2011) and hemodynamic responses (Suzuki et al., 2004) during preparation for, and performance of, stepping over obstacles, as well as during adaptive walking and precision stepping (Koenraadt et al., 2014). A recent study demonstrated that, during gait adaptation, stroke patients prefer step lengthening over step shortening (Roerdink et al., 2009), suggesting that brain mechanisms controlling voluntary gait deceleration and acceleration differ (Varraine et al., 2000). Recent studies have reported that performing a secondary task during walking induces participants to take longer strides (Lovden et al., 2008; Li et al., 2012; De Sanctis et al., 2014), suggesting that step lengthening requires fewer attentional resources.

To examine whether difficulty in gait adaptation is related to PFC $\beta$ band activity, we designed a high-density EEG study in which participants walking on a treadmill moving at a steady rate had to adapt their step length and rate to shifts in the tempo of a pacing tone (e.g., shifts requiring both longer and shorter step adaptation). We expected three different processes to accompany step rate and length adaptations to auditory tempo shifts: (1) $\mu$ and $\beta$ band desynchronization in sensorimotor and parietal cortex, reflecting increased motor

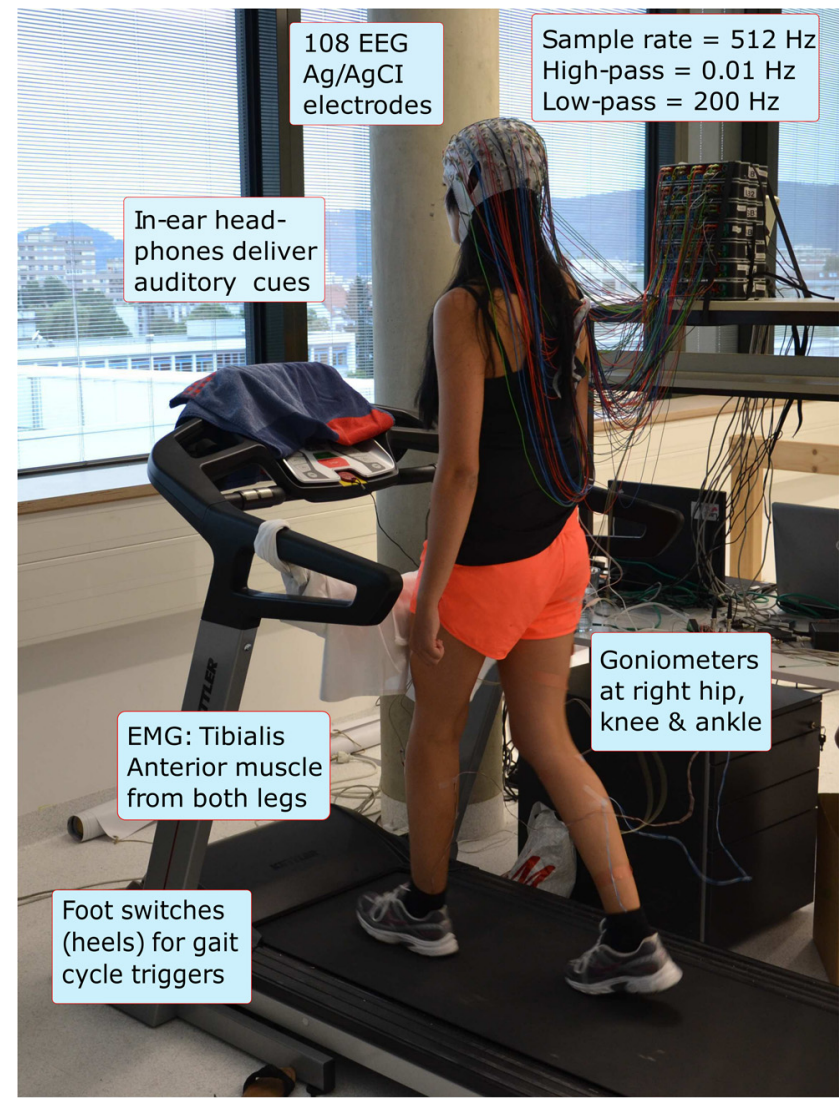

Figure 1. Experimental setup. Participant walking on the treadmill with auditory pacing cues delivered through in-ear headphones. During the initial training period, treadmill speed (3-3.5 km/h) was adjusted to the most comfortable pace for each participant and thereafter remained constant.

flexibility and adaptation; (2) increased $\beta$ band power within the PFC, reflecting additional cognitive control; and (3) scaling of PCF $\beta$ band power changes with task difficulty, producing a stronger increase in $\beta$ band power during step shortening than during step lengthening.

\section{Materials and Methods}

Participants. Twenty healthy volunteers with no neurological or motor deficits participated in this study. The data of two subjects were excluded because of heavy EEG artifact. The remaining data of 18 subjects (10 males and 8 females, 22-35 years of age; mean 29.1 years, SD 2.7 years) were used in the analysis. All participants were right handed. Prior studies show that footedness follows handedness in right handers, although not consistently so in left handers (Peters and Durding, 1979). The experimental procedures were approved by the human use committee of the Medical University Graz. Each subject gave informed consent before the experiment.

Experimental design and procedure. Figures 1 and 2 show the experimental setup and a schematic of the task paradigm, which was adapted from Bank et al. (2011).

Training. Before the experimental procedure, participants practiced walking on the treadmill for 2-3 min. While walking on the treadmill, participants adapted the belt speed to their most comfortable walking speed; this ranged from 3.0 to $3.7 \mathrm{~km} / \mathrm{h}$ across participants. Belt speed was then fixed at the participant's comfortable walking speed and thereafter remained constant throughout the experiment. Next, participants practiced the gait adaptation task with auditory pacing so as to become familiar with the task until they reached acceptable performance, meaning that they correctly responded to step-advance and step-delay pacing signal tempo shifts by shortening or lengthening their steps so as to synchronize their gait to the new pacing tempo. 
Trial structure. During each approximately minute-long trial period, participants first walked without pacing cues for $\sim 10 \mathrm{~s}$. During the next $8-12 \mathrm{~s}$, they heard a stream of auditory cue tones delivered via in-ear headphones at a tempo matching to their current step tempo (the mean of the step intervals between their six most recent uncued steps). The cue sequence was an alternating series of high and low tones presented so as to match the participant's right and left (or left and right) heel strikes, respectively; this high/low assignment was randomized over subjects. Participants were asked to attempt to synchronize their heel strikes to the cue tones.

Next, relative to a randomly selected right heel strike (after 8-12 s of cued steady-state walking), the tempo of the cue sequence was suddenly increased or decreased by one-sixth of a cycle (60 deg) (as in Roerdink et al., 2009), and this new cue tempo was maintained for $30-70$ steps. Participants were instructed to adjust their heel strikes so as to synchronize with the new cue sequence as quickly as possible. The gait adjustments required to restore synchronization with the metronome were as follows: a one-sixth longer step interval and step length in $\left(60^{\circ}\right.$ phase shift) step-delay trials, and a one-sixth shorter step interval and step length in $\left(-60^{\circ}\right.$ phase shift $)$ step-advance trials. After $30-70$ steps at the new step rate, the next trial began immediately with, again, uncued walking, during which participants were instructed to return to their most comfortable step rate.

A total of 60 step-advance and 60 step-delay trials were conducted in 10 blocks of 12 trials, each comprised of 6 step-advance and 6 step-delay trials presented in random order. Between blocks, when asked for by participants, short breaks of 5 min were given during which participants were standing on the treadmill.

Data acquisition. Seven 16-channel amplifiers (g.tec) were combined so as to record EEG data from 108 electrode channels in the 5\% International 10/20 System (EasyCap) (Oostenveld and Praamstra, 2002). Electrode locations that extended below the conventional 10-20 spherical layout included PO9, POO9, OI1, OI2, POO10, PO10, I1, Iz, and I2. Reference and ground electrodes were placed on the left and right mastoids, respectively. All electrode impedances were reduced to $<5 \mathrm{k} \Omega$ before the recording. Electromyographic (EMG) signals were recorded from the skin over the tibialis anterior muscles of both legs using standard adhesive-fixed disposable $\mathrm{Ag} / \mathrm{AgCl}$ surface electrodes. These EMG channels were also recorded using left and right mastoids as reference and ground, respectively. The EEG and EMG data were sampled at 512 $\mathrm{Hz}$, high pass filtered $>0.1 \mathrm{~Hz}$, and low pass filtered $<256 \mathrm{~Hz}$. Foot contacts were measured by mechanical foot switches placed over the calcaneus bone in the heel of each foot. These switches produced event markers for gait cycle heel strike and heel off events. To record the exact timing of the auditory cues, we recorded the auditory stimulation via digital inputs to one of the amplifiers.

Behavioral analysis. Two participant timing error correction processes have been distinguished: (1) period correction to bring the motor acts (here, heel strikes) into the same tempo as the stimulus sequence (Michon, 1967); and (2) phase correction to make the motor acts coincident with pacing stimulus onsets by compensating for any phase difference (Repp, 2001a,b). To assess sensorimotor synchronization, we thus analyzed phase correction and period correction separately. Phase correction was assessed by computing asynchronies between heel strikes and pacing tone onsets (for an overview, see Repp, 2005; Repp and Su, 2013), whereas period correction was assessed by computing temporal differences between cue intervals (time intervals between consecutive cue onsets) and step intervals (or step onset asynchronies, intervals between consecutive heel strikes).

Phase correction. For each trial, the relative phase angle difference between each heel onset and the corresponding auditory cue was calculated. Phase was defined as phase $=360^{\circ} \times($ tcue $-t H S) /$ Tcue, with tcue (in milliseconds) denoting the time of cue onset, tHS denoting the time of the nearest heel strike, and Tcue denoting the time interval between consecutive ipsilateral step cues (Roerdink et al., 2007). For each trial, preshift coordination between steps and cues was quantified by computing the mean and SD phase angle difference in the five steps immediately preceding the tempo shift. The time course of gait adjustments made by the participant to restore coordination following cue tempo shifts was quantified by calculating the phase difference from baseline for the 14 steps following the shift and dividing by \pm 60 so that step phase at $\mathrm{S} 0$ (the first time-perturbed stimulus) was $60^{\circ}$ (Roerdink et al., 2009; Pelton et al., 2010). Trials were excluded from analysis if any of the steps exceeded normalized phase of $180^{\circ}$, which corresponds to a $180^{\circ}$ difference from premanipulation performance. Based on these criteria, on average 5 (SD \pm 6 ) shift trials were excluded ( $6 \%$ of all trials).

A $2 \times 14$ repeated-measures ANOVA with factors "tempo shift" (long vs short) and "step number" (step numbers 1-14 following the shift) was used to assess significant differences in fidelity of adaptation between step-advance and step-delay shifts. Post hoc tests were corrected for multiple comparisons a priori to a significance level of $p<0.05$ using false discovery rate (Benjamini and Yekutieli, 2001).

EEG analysis. EEG data analysis was performed using custom scripts written in MATLAB2014a (The MathWorks) incorporating EEGLAB 14.0b functions (Delorme and Makeig, 2004). In Wagner et al. (2012, 2014), we showed that artifact contamination of the EEG during upright walking can be separated from the brain source data using Infomax Independent Component Analysis (ICA) (compare Onton et al., 2006; Gwin et al., 2010).

The EEG data were high-pass filtered at $1 \mathrm{~Hz}$ (zero phase FIR filter, order 7500 ) to minimize slow drifts, and low pass filtered $<200 \mathrm{~Hz}$ (zero phase FIR filter, order 36). EEG channels with prominent artifacts were identified by visual inspection and removed. On average, 106 channels per participant ( $S D \pm 2.2$; range 102-108) remained for analysis. The EEG data were then rereferenced to a common average reference. After visually rejecting artifacts in the continuous EEG, the data were partitioned into epochs of $0.5 \mathrm{~s}$ and those epochs containing values exceeding the average of the probability distribution of values across the data segments by $\pm 5 \mathrm{SD}$ were rejected. On average, 45 postshift steps per condition $(80 \%$ of each participant's EEG data) remained in the analysis (SD $\pm 11 \%$; range $71 \%-89 \%$ ).

Next, the preprocessed EEG data were decomposed using adaptive mixture ICA (AMICA) (Palmer et al., 2006, 2008). AMICA is a generalization of the Infomax ICA (Bell and Sejnowski, 1995; Makeig et al., 1996) and multiple-mixture (Lee et al., 1999; Lewicki and Sejnowski, 2000) ICA approaches. AMICA performed blind source separation of all concatenated preprocessed data trials for each subject individually, based on the assumed temporal near-independence of the effective EEG sources (Makeig et al., 2002, 2004a).

Using a standardized three-shell boundary element head model implemented in the DIPFIT toolbox within EEGLAB (sccn.ucsd.edu/eeglab), 
we calculated a best-fitting single equivalent current dipole matched to the scalp projection of each independent component (IC) source (Oostenveld and Oostendorp, 2002; Delorme et al., 2012). Standard electrode locations corresponding to the Extended 10-20 System were aligned with a standard brain model (MNI). We retained ICs for further analysis for which the equivalent dipole model was located within the brain and explained $>90 \%$ of variance of the IC scalp map.

We visually inspected the remaining IC scalp maps, event-locked time courses, and mean power spectra to identify ICs related to nonbrain source artifacts (eye movement and scalp/neck muscle artifacts). Nonartifactual ICs were retained for further analysis. For these, feature vectors were constructed coding IC differences in dipole locations, scalp projection maps, and power spectral densities (3-45 Hz) (Makeig et al., 2002). Using principal component analysis, these feature vectors were reduced to 10 principal components and clustered using $k$-means $(k=18)$. ICs were identified as outliers if their locations in the clustering vector space were $>5$ SDs from the obtained cluster centers. Only clusters including ICs from more than half of the participants are reported here.

Cortical IC clusters. Clustering gave three IC source clusters in frontal brain, one cluster in left temporal cortex, one in central midline cortex, and two in parietal areas. None of the obtained clusters included sources from all participants. Therefore, we inspected more closely the ICs included and excluded from each cluster. For the frontal clusters, all ICs with an equivalent dipole in these brain areas exhibited event-related spectral perturbations (ERSPs) consistent with nearby ICs and were therefore included in a frontal source cluster. These clusters "missed" ICs from 5, 3, and 1 subjects, respectively. Parietal ICs omitted from parietal clusters were located either more anterior or more occipital relative to cluster ICs. The one temporal cluster included ICs from three participants whose ERSPs contained broadband spectral perturbation features possibly related to muscle artifact. These ICs were therefore removed from the cluster. ICs in central brain regions were somewhat more heterogeneous. Eleven of the 18 subjects contributed an IC to the central midline cluster. Components from the other 7 participants did not show a similar spectral pattern (4 ICs) or (3 ICs) had scalp maps that looked noisy, such that the associated dipoles explained $<90 \%$ of variance of the IC scalp map and were thus excluded or were oriented differently than other cluster ICs.

There are several possible explanations for failures of some subjects' data to contribute an IC to an IC cluster. Possibly because of subject differences in channel noise, signal variability, or data quantity, ICA decomposition and/or IC clustering might not have been able to resolve or properly group these brain sources. Possibly, the presence of more spatially variegated artifacts in some subjects reduced the number of degrees of freedom in the data available for isolating brain source processes. Finally, the possibility that ICs "missing" from a cluster index actual differences in brain processing across subjects should not be rejected out of hand (Onton et al., 2005).

ERSPs. The data were segmented into time epochs relative to onsets of cue tempo shifts (i.e., from -4 to $10 \mathrm{~s}$ around the first right shift related heel strike). ERSPs (Makeig, 1993) were computed for each IC. Singletrial spectrograms were computed and time warped to the median step latency (across subjects) using linear interpolation. This procedure aligned time points of right and left heel strikes over trials for the 7 heel strikes preceding and the 15 heel strikes following each tempo shift. Relative changes in spectral power were obtained by computing the mean difference between each single-trial log spectrogram and the mean baseline spectrum (the average log spectrum between $-4 \mathrm{~s}$ and $-0.5 \mathrm{~s}$ preceding tempo shifts). Significant deviations from the baseline were detected using a nonparametric bootstrap approach (Delorme and Makeig, 2004). Figure 3 gives an overview of the analysis pipeline.

To compute significant differences between step-advance and stepdelay shifts, individual frequency bands were selected per subject by determining ranges from $8-13 \mathrm{~Hz}(\alpha), 14-20 \mathrm{~Hz}$ (lower $\beta$ ), and $21-35 \mathrm{~Hz}$ (upper $\beta$ ) and choosing the frequency band with maximally varying power modulation over time. For statistical analysis, ERSPs relative to step-advance and step-delay shifts were computed by time warping single trial spectrograms to the same (group median) step latencies and subtracting the overall mean log spectrum for both conditions computed from $-4 \mathrm{~s}$ to $-0.5 \mathrm{~s}$ before the tempo shift. For statistical analysis, we selected four time windows centered on the first left (L1) and second right (R2) steps following tempo shifts.

A $2 \times 4$ repeated-measures within-subject ANOVA with factors "tempo shift" (long vs short) and "step number" (4 time windows) was computed for each IC cluster and each frequency range ( $\alpha$, lower $\beta$, upper $\beta$ ) in the (individually subject-selected) dominant frequency range. Multiple comparisons were addressed by controlling for false discovery rate (Benjamini and Yekutieli, 2001) with an a priori significance level of $p<0.05$. In cases in which the assumption of sphericity was violated, significance values were corrected using Greenhouse-Geisser.

ERPs. To understand better the origin of ERSPs relative to the tempo shifts in the auditory cue sequence (cue tempo shift) (e.g., whether the tempo shift ERSP features were more related to the auditory perception of the cue tempo shifts or to the behavioral modification of step timing), we analyzed averaged ERPs time-locked to the presentation of the first tempo-adjusted cue tones. In particular, this analysis revealed the latency following cue onset at which participants' EEG signals first showed a reaction to the cue tempo shift, suggestive of the time point at which participants perceived the cue tempo shift. Comparing this latency to the latencies of the step-locked ERSP features of interest might indicate whether these ERSP features were related to the perception of the cue tempo shift itself or to the implementation of the responsive behavioral adaptation. Accordingly, ERPs were computed relative to (1) the first cue tone indicating a tempo shift (Rcue) and (2) the step (Rstep) nearest in time to the Rcue. We also assessed ERPs relative to cues and steps in a control condition consisting of steady-state walking to an auditory cue sequence without tempo shift (cue no shift). We computed cluster mean ERPs and their $90 \%$ confidence intervals for IC processes in frontal, temporal, and central midline clusters, respectively. Next, to assess differences between cue- and step-locked ERPs, we shifted steplocked ERPs by the median latency between Rstep and Rcue, so that latency 0 in step-locked ERP plots corresponded to the median Rcue latency.

On the cortical origin of ERSPs during walking. Two recent studies (Castermans et al., 2014; Kline et al., 2015) investigated movementrelated artifacts in the EEG during upright walking and found contamination of the EEG data at frequencies from 1 to $150 \mathrm{~Hz}$. Castermans et al. (2014) found similar time/frequency properties in accelerometer signals recorded from the head during walking and in EEG for frequency bands extending up to $150 \mathrm{~Hz}$. To record pure movement artifacts from EEG electrodes on the human head, Kline et al. (2015) blocked electrophysiological signals by wearing a silicone swim cap as a nonconductive layer under a standard EEG cap. They observed movement artifacts, depending on walking speed and electrode location, from 1 to $150 \mathrm{~Hz}$. In a follow-up analysis (Snyder et al., 2015), the same authors applied ICA to this pure artifact data. They showed that $99 \%$ of the obtained sources lacked dipolar characteristics and were located outside the head, whereas only $1 \%$ of the sources were localized inside the brain with residual variance $<15 \%$. These component processes, however, had scalp maps, time courses, power spectra, and time-frequency changes much more typical of movement artifacts rather than brain source processes. Thus, movement artifacts do induce broadband frequency changes in signals recorded at scalp electrodes, but these nonbrain artifacts can be reliably identified and separated from brain source signals using ICA.

Scalp and neck muscle activities can also contaminate EEG signals during movement (Gramann et al., 2010; Gwin et al., 2010, 2011; Seeber et al., 2014). Scalp EMG artifacts appear across frequencies $>20 \mathrm{~Hz}$ (Muthukumaraswamy et al., 2013; Castermans et al., 2014). By contrast, many EEG and electrocorticography studies show that electrocortical oscillations relative to motor or cognitive processing synchronize or decrease in narrow frequency bands, including $\mu(7-12 \mathrm{~Hz})$ and $\beta(15-30$ $\mathrm{Hz}$ ) during restricted lower limb movements (Pfurtscheller et al., 1997; Crone et al., 1998; Miller, 2007; Müller-Putz et al., 2007) and walking (Wagner et al., 2012, 2014; Severens et al., 2012; Seeber et al., 2014). Broadband high-frequency power changes (within and beyond the $\gamma$ band) have been suggested to play a distinct role in cortical processing (Onton and Makeig, 2009; Miller et al., 2014). Because cortical signals, 


\section{Decompose single-subject 108 channel EEG data with AMICA}

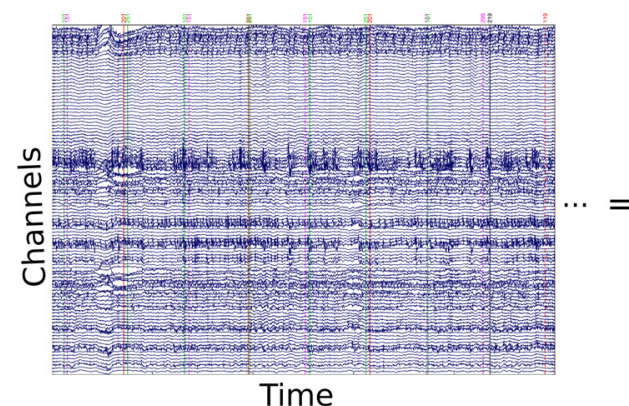

Time

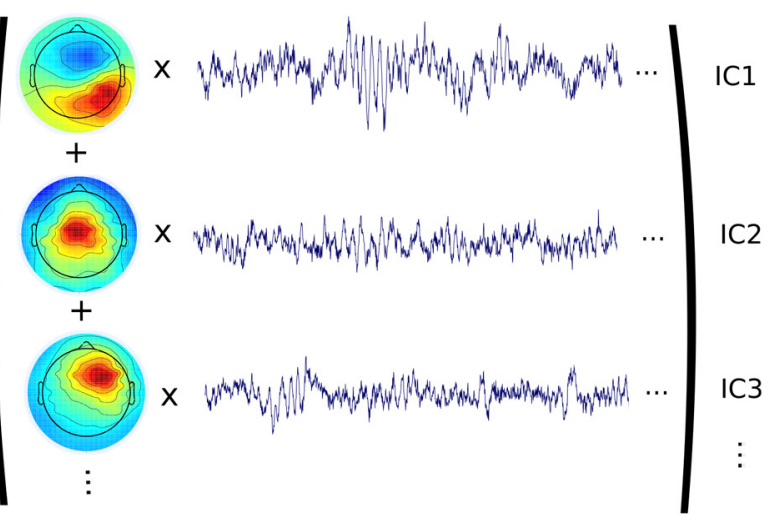

3. Identify \& deselect non-brain artifact ICS

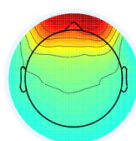

Vertical eye movements

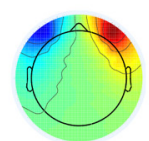

Horizontal eye movements

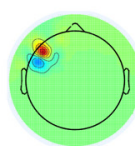

Muscle activity

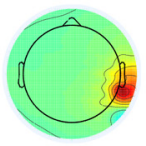

Muscle activity

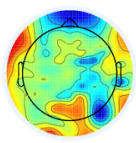

Noise

\section{Compute single-IC ERSPs}

4. Cluster remaining brain ICs across subjects based on

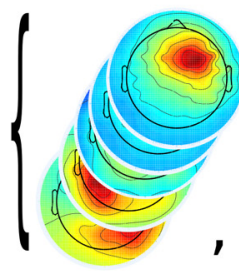

IC maps

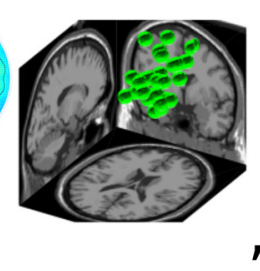

IC equiv. dipoles

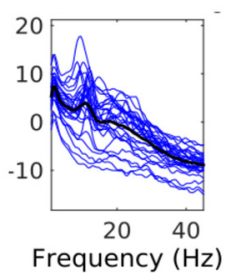

IC spectra

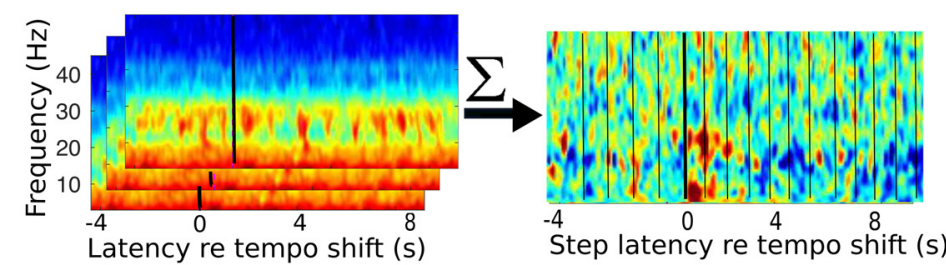

For each IC: Time lock (and time warp) single-trial log spectograms (left) to step heel strikes before and after the tempo shift; average these (right), subtract the mean log pre-shift spectrum.

\section{Compute IC-cluster mean ERSPs}
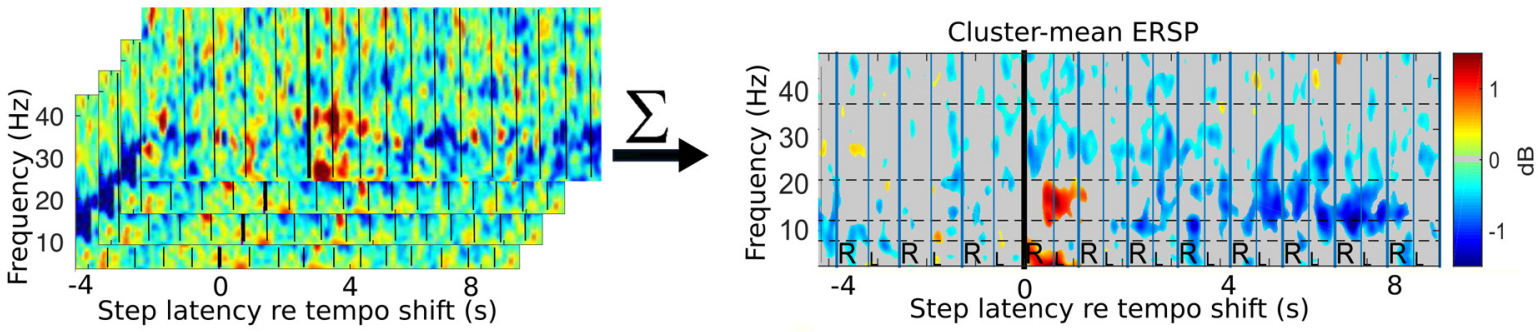

For each IC-cluster: Average single IC-ERSPs for ICs in the cluster (left); compute cluster-mean ERSP significance level; mask non-significant regions in grey (right).

Figure 3. Schematic overview of the EEG data-processing pipeline. (1) Single-subject data are decomposed by AMICA into maximally IC time courses (traces) with spatially fixed projections (scalp maps). (2) Single equivalent current dipole locations are estimated. (3) Nonbrain artifact sources are identified and removed from further processing. (4) Brain source ICs are clustered across subjects based on their scalp maps, dipole locations, and log power spectra. (5) Single trial spectrograms and mean, base spectrum-removed ERSP for one IC. (6) Single-IC ERSPs and IC Cluster-mean ERSP relative to step-advance time shifts for the right frontal cluster.

biological noise, and mechanical artifacts possess distinct properties in waveform, frequency range, and spatial distribution, proper application of signal processing methods allows separation of these sources (Makeig et al., 1996; Gwin et al., 2010; Wagner et al., 2012; Seeber et al., 2014, 2015; Snyder et al., 2015).

In two previous studies (Wagner et al., 2012, 2014), we showed that considering carefully the location, time course, and the frequency spectra of the single independent components separated by ICA decomposition allows identification of sources related to brain activity. For a more detailed report on the artifacts during walking, see Wagner et al. (2012). Our previous results (Wagner et al., 2012, 2014; Seeber et al., 2014,2015) on $\beta$ band suppression and high $\gamma$ increases related to walking are in line with findings in the literature on the functional role of these rhythms in motor execution (Pfurtscheller et al., 1997; Crone et al., 1998; Miller, 2007; Müller-Putz et al., 2007). Additionally, the relatively slow walking speeds used in our studies have been found in previous studies not be heavily affected by artifacts (Gwin et al., 2010). This accumulated evidence indicates that the observed frequency-specific power modulations in the EEG presented in our current and previous studies are of cortical origin. 
A

Right frontal cluster (17 Ss, 19 ICs)
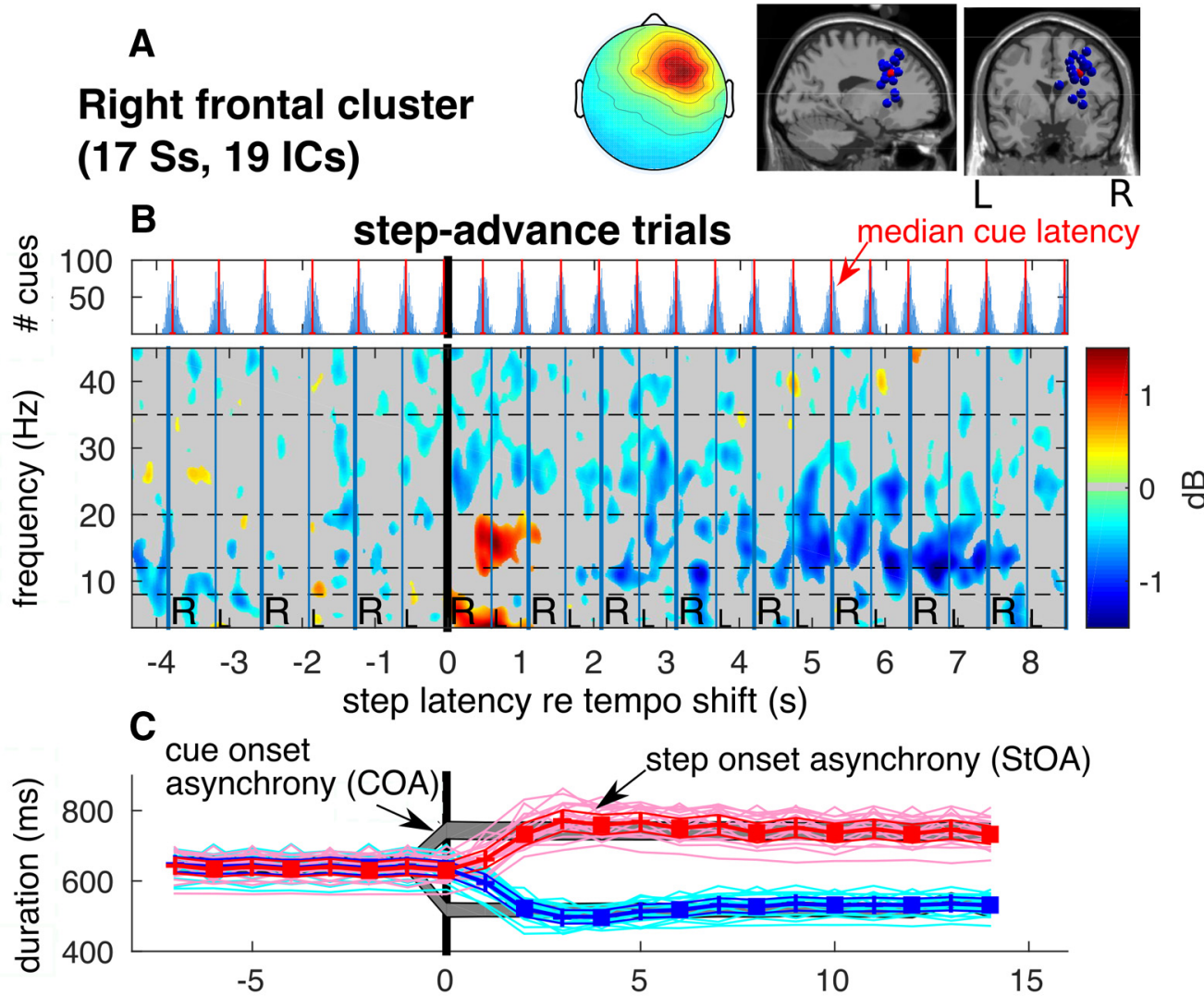

D
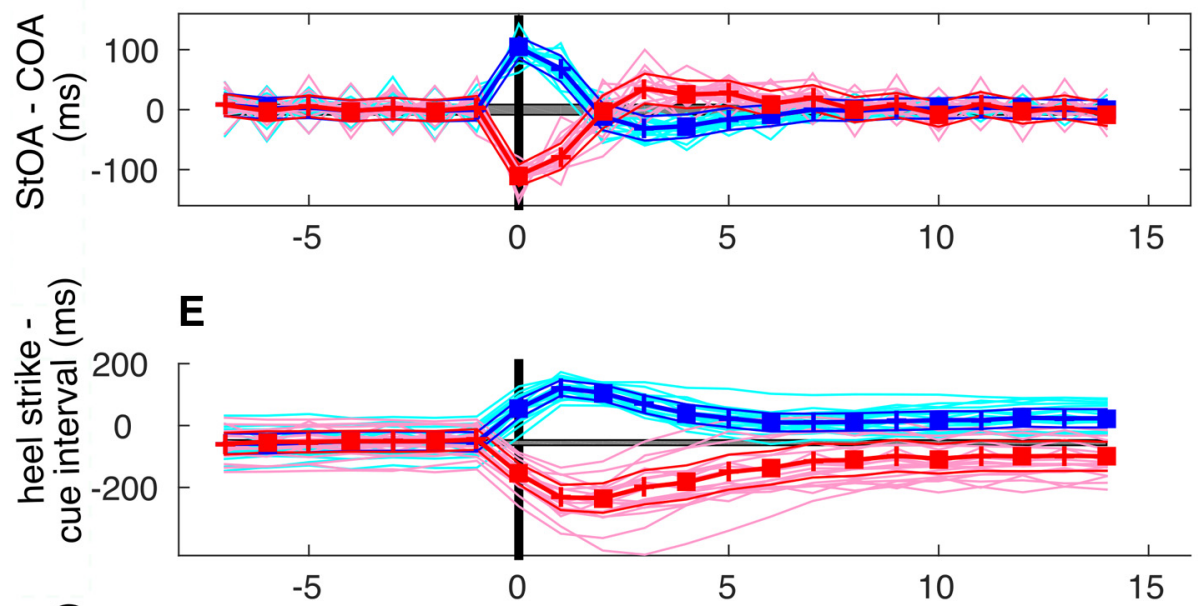

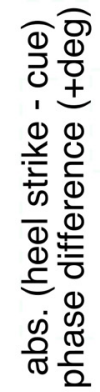

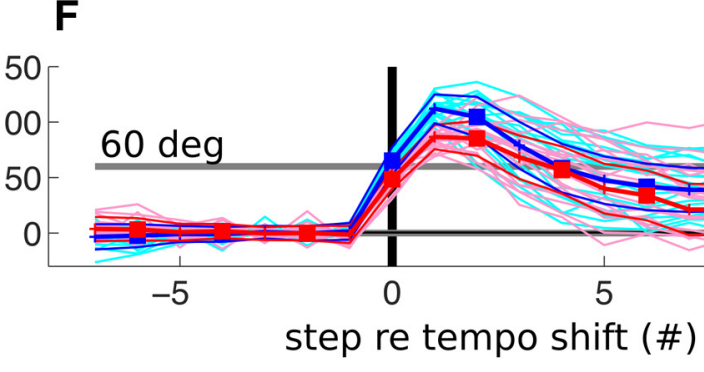

5

Figure 4. ERSP image and behavioral adaptation following tempo shifts. A, Cluster mean scalp projection map and equivalent dipole locations of cluster ICs (blue spheres) and their centroid (red sphere) visualized in the MNI template brain and centered in r-dIPFC. B, Cue latency histograms (above) and cluster mean ERSP image (below) for the r-dIPFC IC source cluster in step-advance (step shortening) trials. Single-trial spectrograms were computed between -4 and $10 \mathrm{~s}$ around the first time-shifted cue ( $0 \mathrm{~s}$ indicates the target right heel strike). (Figure legend continues.) 
Table 1. IC clusters and cluster centroid locations

\begin{tabular}{llrll}
\hline Cluster & $\begin{array}{l}\text { No. of subjects/ } \\
\text { sources }(\mathrm{ICs})\end{array}$ & $\begin{array}{l}\text { Tailarach } \\
\text { coordinates }\end{array}$ & $\begin{array}{l}\text { Brodmann } \\
\text { area }\end{array}$ & Cortical location \\
\hline Left temporal & $13 / 14 \mathrm{ICs}$ & $-42,-10,-5$ & BA21 & Temporal lobe \\
Frontal central & $15 / 15 \mathrm{ICs}$ & $-1,39,31$ & BA9 & Medial prefrontal cortex \\
Left frontal & $13 / 15 \mathrm{ICs}$ & $-28,20,25$ & BA9 & Dorsolateral prefrontal cortex \\
Right frontal & $17 / 19 \mathrm{ICs}$ & $28,20,29$ & BA9 & Dorsolateral prefrontal cortex \\
Central midline & $11 / 11 \mathrm{ICs}$ & $3,-2,47$ & BA6 & Supplementary motor area \\
Left parietal & $14 / 16 \mathrm{ICs}$ & $-34,-29,42$ & BA40 & Parietal cortex \\
Right parietal & $13 / 16 \mathrm{ICs}$ & $35,-44,37$ & BA40 & Parietal cortex \\
\hline
\end{tabular}

\section{Results}

\section{Behavioral analysis}

The step onset asynchrony (StOA) before tempo shifts was on average $641 \mathrm{~ms}(\mathrm{SD} \pm 5.3 \mathrm{~ms}$ ). Following tempo shifts, a new stable StOA was generally achieved within $3 \pm 1$ steps, as shown in Figure $4 C$. Step-delay shifts $\left(60^{\circ}\right)$ produced increases in both StOA (754 ms, calculated for the first 15 steps following shifts; $\mathrm{SD} \pm 14 \mathrm{~ms})$ and step length, whereas step-advance shift $\left(-60^{\circ}\right)$ produced decreases in StOA (mean time between steps, $523 \mathrm{~ms}$; $\mathrm{SD} \pm 13 \mathrm{~ms}$ ) and step length. These changes were fairly large, on average $18 \%$ relative to baseline, slightly larger than the expected one-sixth (16.7\%), although not significantly so.

\section{Period correction}

The evolution of adjustments in step rate to the two new pacing tempi for all participants are depicted in Figure $4 D$, which also shows the mean difference between StOA and cue onset asynchrony (COA). On average, step period adaptation was achieved within the first two steps (between L1 and R2). During the four following steps, an overcorrection (R2) occurred, after which participants stepped in near-exact synchrony to the new pacing sequence.

\section{Phase correction}

Negative StOA - COA differences indicate that, during steady state, cue-synchronous walking step onsets slightly preceded stimulus onsets. During walking at the preferred cadence (e.g., steps -7 to -1 before the shift), we observed that heel strikes were consistently ahead of the cues (mean difference, $-59 \mathrm{~ms}$; $\mathrm{SD} \pm 43 \mathrm{~ms}$ ) as shown by comparing the cue latency histograms with the median step latencies in the ERSP plot in Figure $4 B$ and as evidenced by the negative pre-shift heel strike minus cue difference in Figure $4 E$. This difference matches a well-known phenomenon called "phase lead" in finger tap synchronization

\section{$\leftarrow$}

(Figure legend continued.) To construct the group-mean ERSP for each subject, the singletrial EEG spectrograms were first time warped to the group-median latencies of the heel strikes during the imaged interval (red vertical lines in the cue latency histograms). Relative changes in spectral power were obtained by subtracting the mean log spectrum in the interval $-4 \mathrm{~s}$ to -0.5 s before the shifts. Nonsignificant changes from baseline are masked in gray. Vertical lines indicate right and left heel strikes. R's and L's indicate right and left foot placements, respectively. Dashed horizontal lines indicate $\alpha(8-13 \mathrm{~Hz})$, lower $\beta(13-20 \mathrm{~Hz})$, and upper $\beta(20-35$ $\mathrm{Hz}$ ) bands. The ERSP plot shows, first, a synchronization in the $\beta$ band between the second and third heel strikes following the tempo shift, and then later a desynchronization with respect to baseline. C, Behavioral record: Median step onset asynchronies (StOAs) (blue and red traces) for each subject in the two conditions (step advance and delay), and cue onset asynchronies (COAs) (gray traces) in milliseconds. D, Difference between StOA and COA at each step; this reflects adaptation of step frequency to the perturbed pacing cue tempo. $\boldsymbol{E}$, Time intervals (in milliseconds) between heel strikes and nearest cue onsets reflect sensorimotor synchronization performance (e.g., step adaptation to the tempo-shifted cue sequence). $\boldsymbol{F}$, Absolute step-cue phase difference (in degrees of the baseline cue cycle). studies. It has been suggested that this difference approximates the difference between the times of delivery of the sensory information from the tip of the finger and the auditory information from cue onset to the cortical areas in which their timing is compared. Thus, to establish synchrony at the level of central representations, finger taps should precede the auditory signals (Aschersleben and Prinz, 1995, 1997). Adjustment of steps relative to cues was achieved within 6 steps following tempo shifts. As shown in Figure 4E, the phase lead between steps and cues (measured from steps $7-15$ following the shift) became larger in step-delay (step lengthening) trials (mean, $-122 \mathrm{~ms} ; \mathrm{SD} \pm 61 \mathrm{~ms}$ ) and became positive in step-advance (step shortening) trials (mean, $19 \mathrm{~ms}$; SD \pm 36 $\mathrm{ms})$.

Calculation of the normalized relative phase revealed differences in adaptation relative to positive and negative step rate changes, respectively. The direction of the tempo shift significantly affected synchronization accuracy (significant interaction, $\left.F_{(13,221)}=5.2, p=0.00025\right)$. Post hoc tests revealed a significantly larger initial phase deviation at steps L1 and R2 in step-advance compared with step-delay trials. Also, as shown in Figure $4 F$, when participants reached stable postshift cue synchronization, asynchronies between steps and cues were significantly larger in step-advance than in step-delay trials. This suggests that participants had fewer difficulties in adapting to step-delay compared with step-advance shifts.

\section{Cortical IC source clusters}

Together, three IC source clusters in frontal brain, one cluster in left temporal cortex, one in central midline cortex, and two in parietal areas showed event-related changes in $\alpha$ and $\beta$ band power following cue tempo shifts. The numbers of subjects and sources contained in each cluster as well as Tailarach coordinates of the cluster centroids are given in Table 1.

\section{ERP features}

Cue-locked ERPs in the left temporal and in the right frontal clusters (Fig. 5A) clearly show an "N100-like" negative deflection near $100 \mathrm{~ms}$ (right frontal cluster) or $150 \mathrm{~ms}$ (left temporal cluster) during all three conditions (cue advance, cue delay, and cue no shift) (Fig. 5A). An early negative (N100) peak in anterior scalp electrode channels has been related to auditory processing (Parasuraman, 1980; Makeig et al., 1997). Cluster ERPs for the frontal central and right frontal cluster include positive deflections near $250 \mathrm{~ms}$ in cue delay and at $300-400 \mathrm{~ms}$ in cue advance tempo shifts, although not in the cue no shift condition. A frontal positive deflection near $300 \mathrm{~ms}$ after a target stimulus onset [P300 or late positive component (LPC)] typically follows the detection of novel, rare, or unpredicted sounds (Makeig et al., 2004; Debener et al., 2005; Luck and Kappenman, 2011). In the central midline cluster, we observed a negative peak in the ERP near 250 $\mathrm{ms}$ following cue delay tempo shifts. A small but significant negative deflection $100 \mathrm{~ms}$ later occurred following cue advance shifts (in Fig. 5, the 90\% confidence interval does not include zero). This peak approximates the location and timing of the feedback related negativity (FRN) following presentation of feedback indicating that the participant has committed a response error (Holroyd and Coles, 2002; Hajcak et al., 2006).

Compared with cue-locked ERPs, step-locked ERPs lacked N100-like ERP peaks and exhibited smaller negative and positive peaks in the 250-300 ms interval (Fig. 5B). Cue-locked ERP peaks following cue delay tempo shifts were significantly larger than step-locked ERP features, suggesting that the observed P300- and FRN-like ERP peaks are related to the detection of the 


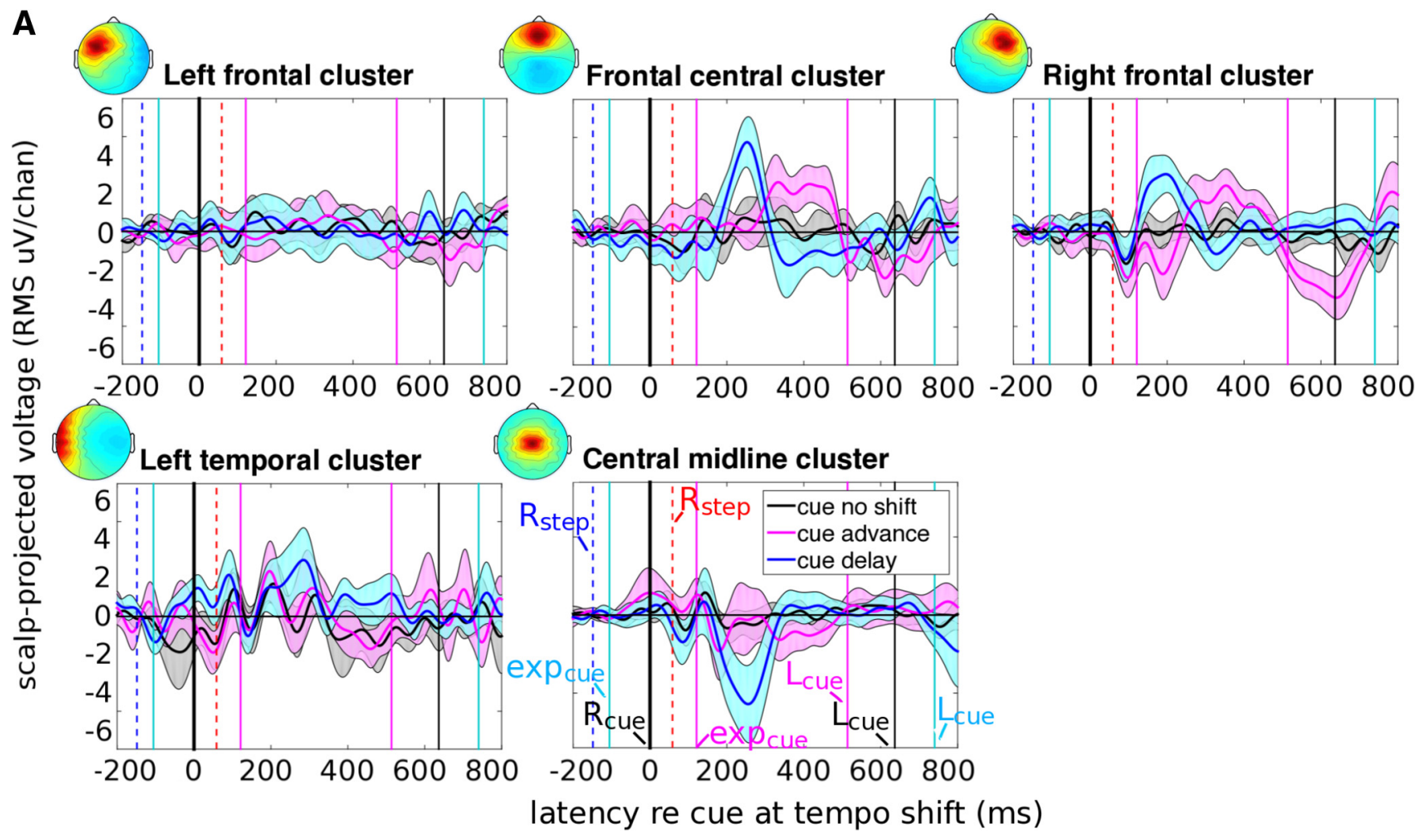

B

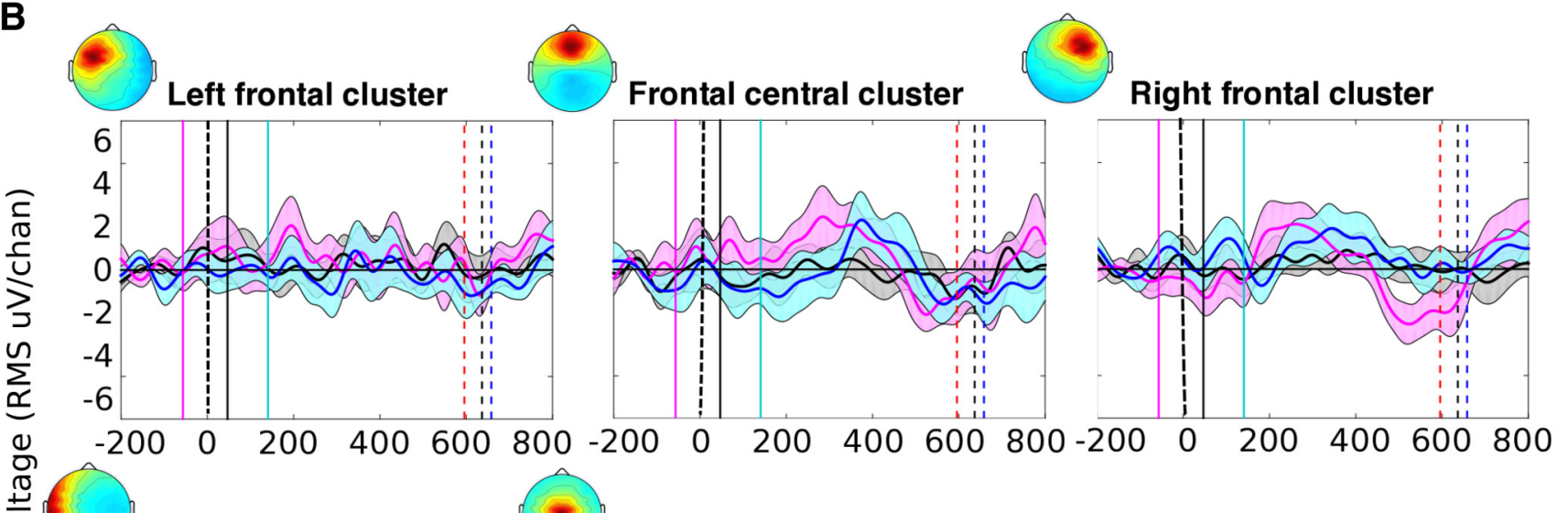

Left temporal cluster

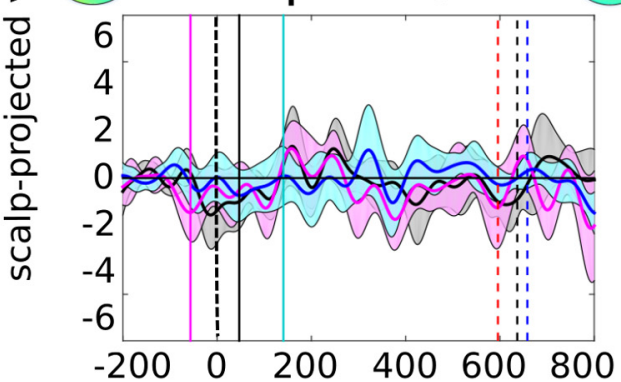

Central midline cluster

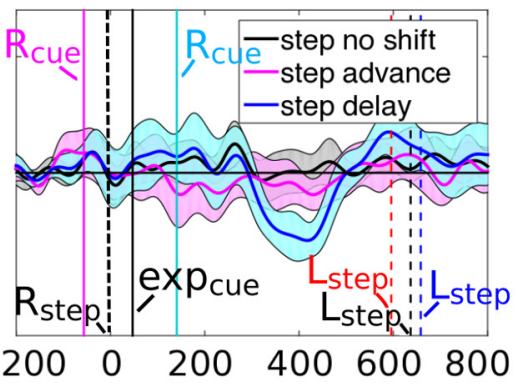

latency re step at tempo shift (ms)

Figure 5. ERPs time-locked to cues and steps at tempo shifts in cue advance, cue delay, and control cue no tempo shift conditions for frontal, temporal, and central midline clusters. Zero marks $(\boldsymbol{A})$ the first cue indicating a tempo shift $\left(\mathrm{R}_{\text {cue }}\right),(\boldsymbol{B})$ the step $\left(\mathrm{R}_{\text {step }}\right)$ related to $\mathrm{R}_{\text {cue, }}$, $(\boldsymbol{A}, \boldsymbol{B})$ simply the cue/step during steady-state walking (control condition). Dashed vertical lines mark right $\left(\mathrm{R}_{\text {step }}\right)$ and left $\left(L_{\text {step }}\right)$ heel strikes. Continuous vertical lines mark cues $\left(R_{\text {cue, }} L_{\text {cue }}\right)$ related to $R_{\text {step }}$ and $L_{\text {step }}$ and the expected occurrence of cues (exp $\left.p_{\text {cue }}\right)$ at tempo shifts. Event-locked time courses indicate averaged cluster ERPs relative to cue/step -advance (pink), -delay (blue), and -no tempo shift (black). Envelopes represent $90 \%$ confidence intervals around means. $A$, During all three conditions (cue advance, cue delay, and cue no shift), cue-locked ERPs feature a prominent negative deflection near $100 \mathrm{~ms}$ (right frontal cluster) or $150 \mathrm{~ms}$ (left temporal cluster). Frontal central and right frontal cluster ERPs include a positive peak near $250 \mathrm{~ms}$ after tempo shifts for cue delay and $300-400 \mathrm{~ms}$ for cue advance but are absent for the cue no shift condition. In the central midline cluster, following cue delay tempo shifts, a negative peak appears near $250 \mathrm{~ms}$. Following cue advance tempo shifts, a small but significant negative deflection occurs $100 \mathrm{~ms}$ later. $\boldsymbol{B}$, Step-locked ERPs exhibit similar but smaller ERP peaks $250-300$ ms after $R_{\text {step }}$. 


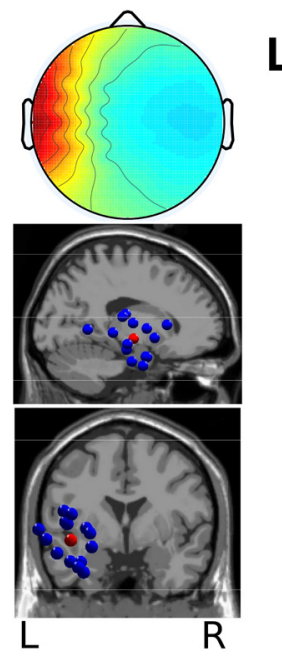

\section{Left temporal cluster (13 Ss, 14 ICs)}
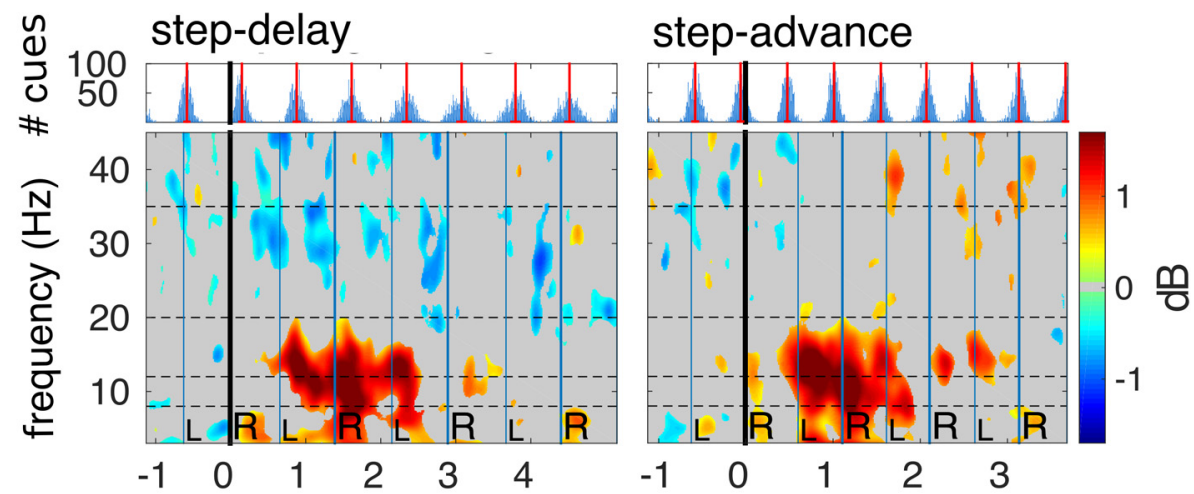

step latency
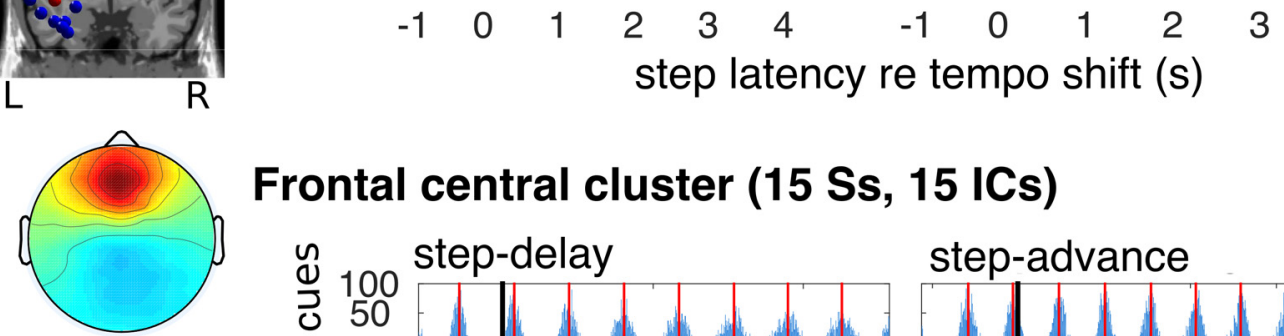

Frontal central cluster (15 Ss, 15 ICs)
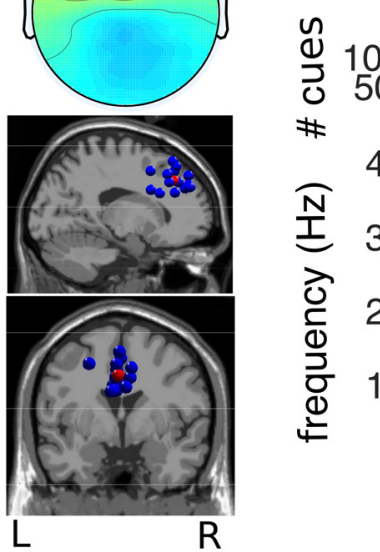

step-advance
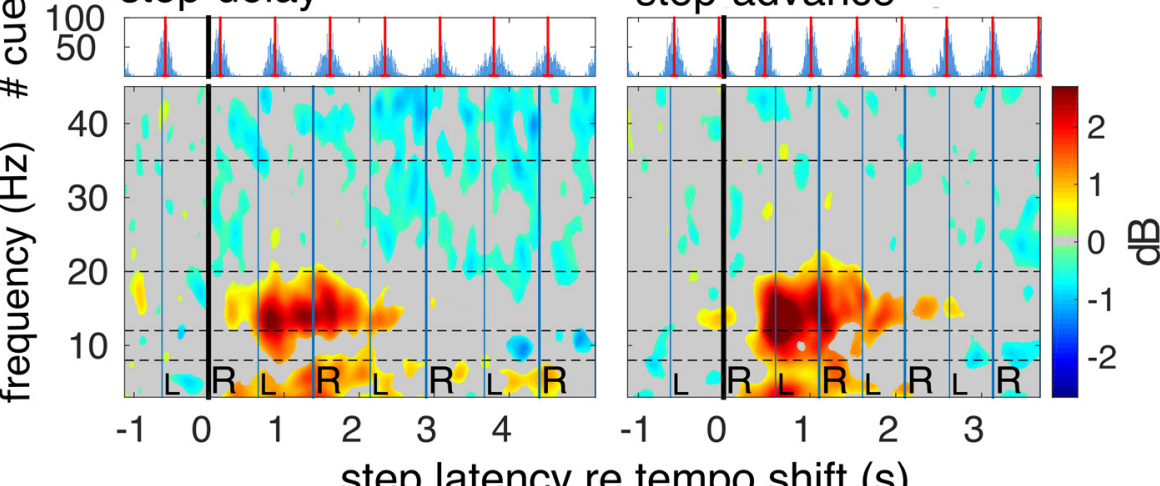

$\begin{array}{lllll}-1 & 0 & 1 & 2 & 3\end{array}$

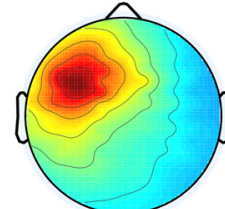

\section{Left frontal cluster (13 Ss, 15 ICs)}
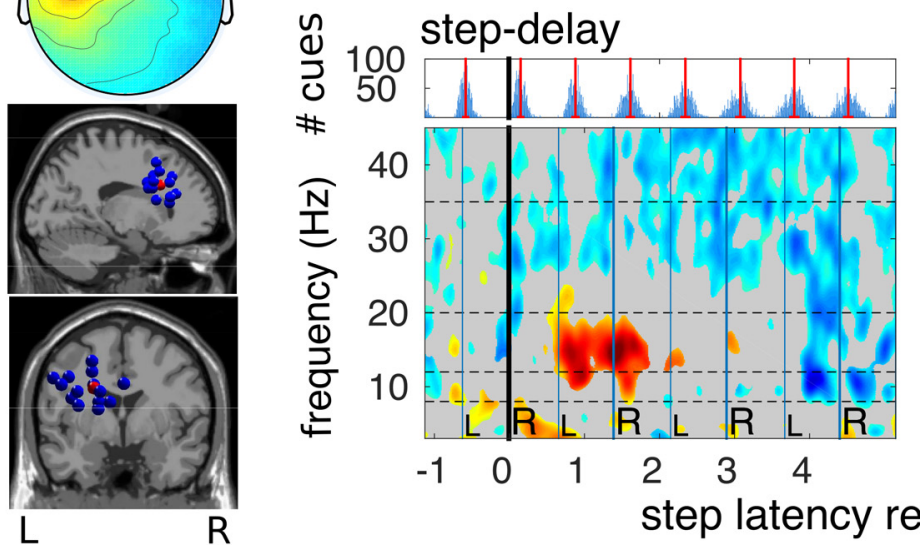

step-advance
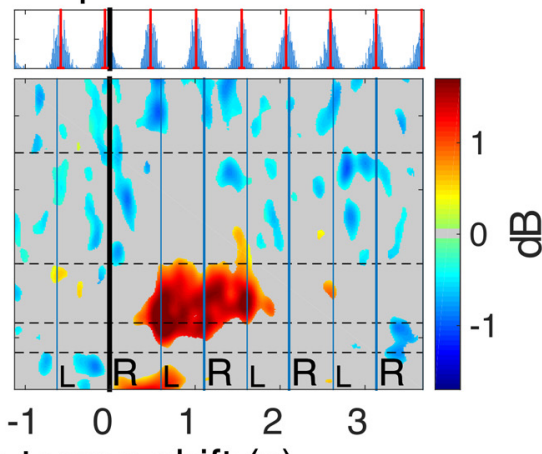

Figure 6. Equivalent dipole source locations and cluster-mean scalp projections and ERSP images for IC source clusters centered in temporal and frontal cortex. From left to right in each row, Mean scalp projection; equivalent dipole locations of cluster ICs; cue onset histogram and cluster-mean ERSP images time-locked to (left) step lengthening (step delay) and (right) shortening (step advance) tempo shifts as marked by the onset of the first time-shifted cue (the nearest cue to the right heel strike at $0 \mathrm{~s}$ ). Single-trial log spectrograms were time warped to median step latencies before averaging. Mean log power at each frequency from $-4 \mathrm{~s}$ to $-0.5 \mathrm{~s}$ before the tempo shift was subtracted to obtain relative changes in log spectral power. Nonsignificant changes from baseline are masked in gray. All three IC clusters show increases in mean $\beta$ band power between the second and fourth heel strikes following the shift.

cue tempo shift. Following cue advance tempo shifts, significant differences between cue-locked and step-locked ERPs appeared only for N100-like ERP components but not for P300- and FRNlike ERP components. One possible explanation would be that, during cue advance tempo shifts, the premature cue tone as well as the step about to be taken are perceived as deviant. Thus, processing of cue advance tempo shifts is possibly related to both the steps and the cues. 
Right frontal cluster (17 Ss, 19 ICs)

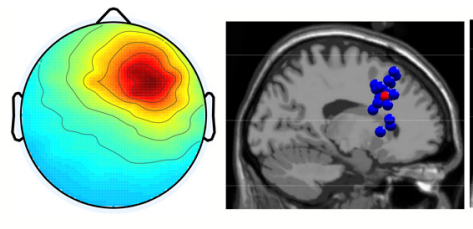

step-advance

ป

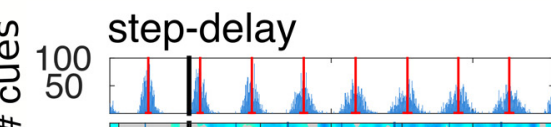

40

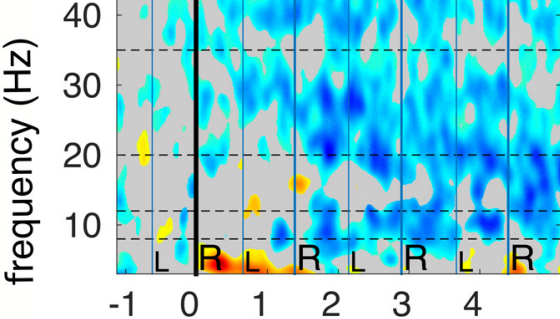

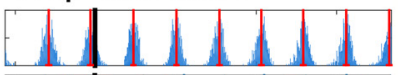

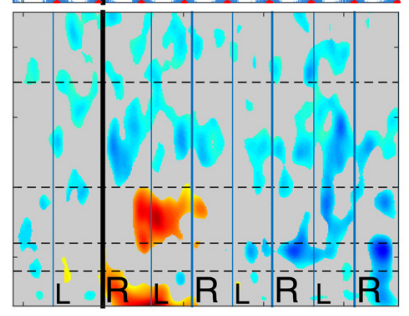

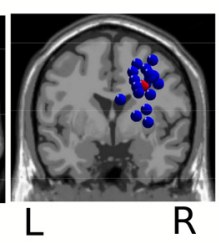

step-advance step-delay difference

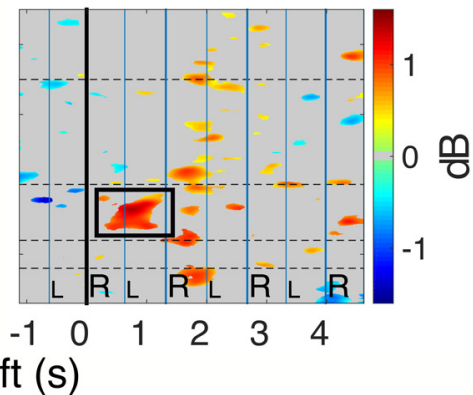

Figure 7. Significant ERSP differences between adaptations to step-advance and step-delay tempo shifts for an IC cluster centered in right dorsolateral frontal cortex. Top, Mean scalp projection and equivalent dipole locations of cluster ICS. Bottom (above), Cue tone onset histograms and (below left, center) cluster-mean ERSP images for step-delay and step-advance trials, respectively, time-locked $(0 \mathrm{~s})$ to the right heel strike nearest to the first tempo-shifted cue tone, and (right) the difference between these two adaptation responses. Significance of condition differences was estimated using a bootstrap approach corrected for multiple comparisons using false discovery rate. Nonsignificant differences are masked in gray. The difference ERSP shows a stronger $\beta$ band power increase near the second and third post-shift steps in the step-advance condition than in (subjectively easier) step-delay adaptations.

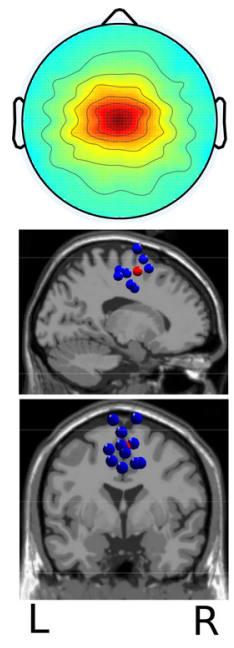

\section{Central midline cluster (11 Ss, $11 \mathrm{ICs})$}

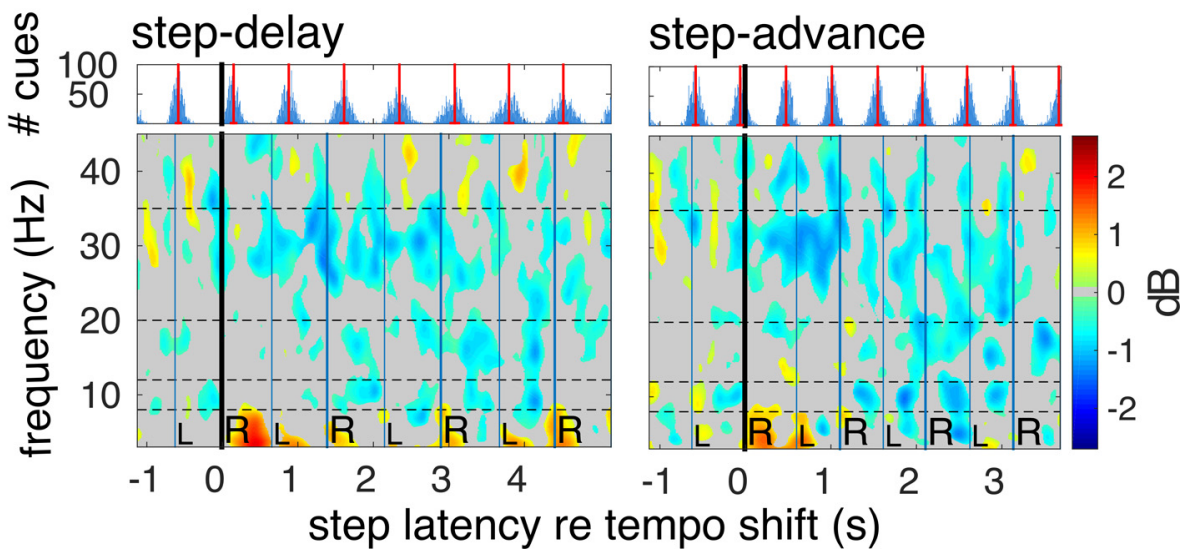

Figure 8. Equivalent dipole source locations and cluster-mean scalp projections and ERSP images for an IC source cluster centered in the supplementary motor area. Cluster-mean ERSP images time-locked to step lengthening and step shortening tempo shifts include desynchronization in the upper $\beta$ band $(25-35 \mathrm{~Hz})$.

The N100-like negative deflections in cue-locked ERPs in the left temporal and right frontal cluster for all conditions (cue advance, cue delay, and cue no shift) indicate that processing of the auditory cue events was ongoing at $100 \mathrm{~ms}$ after Rcue. The P300and FRN-like ERP peaks following cue advance and cue delay tempo shifts, not present in the no shift cue condition, indicate that participants perceived the cue tempo shifts by 250-300 ms after Rcue onsets.

\section{ERSPs}

Figure $4 A, B$ shows cluster location and mean cluster spectral shifts time-locked to step-advance shifts for the right frontal cortex cluster. Comparing spectral shifts (Fig. $4 B$ ) and behavioral data (Fig. $4 C-F$ ), a right frontal $\beta$ band increase coincides with the main adaptation period during steps $2-4$ following the shift.
While, as shown in Figures $4 B$, 6, and 7, during the first four steps after the shift frontal and temporal clusters exhibited significant transient increases in $\alpha$ and/or $\beta$ power $(13-20 \mathrm{~Hz}$ in frontal clusters, $7-20 \mathrm{~Hz}$ in the left temporal cluster), $\mu$ and $\beta$ band power in central midline and parietal clusters decreased during this time period (Figs. 8, 9). Interestingly, for the left and right parietal clusters (Fig. 9), this desynchronization lasted at least 15 steps following tempo shifts and was most pronounced just before contralateral heel strikes. The parietal cluster desynchronization was prominent and long lasting in two frequency bands: $\mu$ $(7-12 \mathrm{~Hz})$ and high $\beta(18-30 \mathrm{~Hz})$.

In central medial sources (Fig. 8), however, the desynchronization was not as strong but included higher frequencies (up to 35 $\mathrm{Hz}$ ) and began immediately following tempo shifts. Only the right frontal cluster showed a significant ERSP difference be- 
Left parietal cluster (14 Ss, 16 ICs)
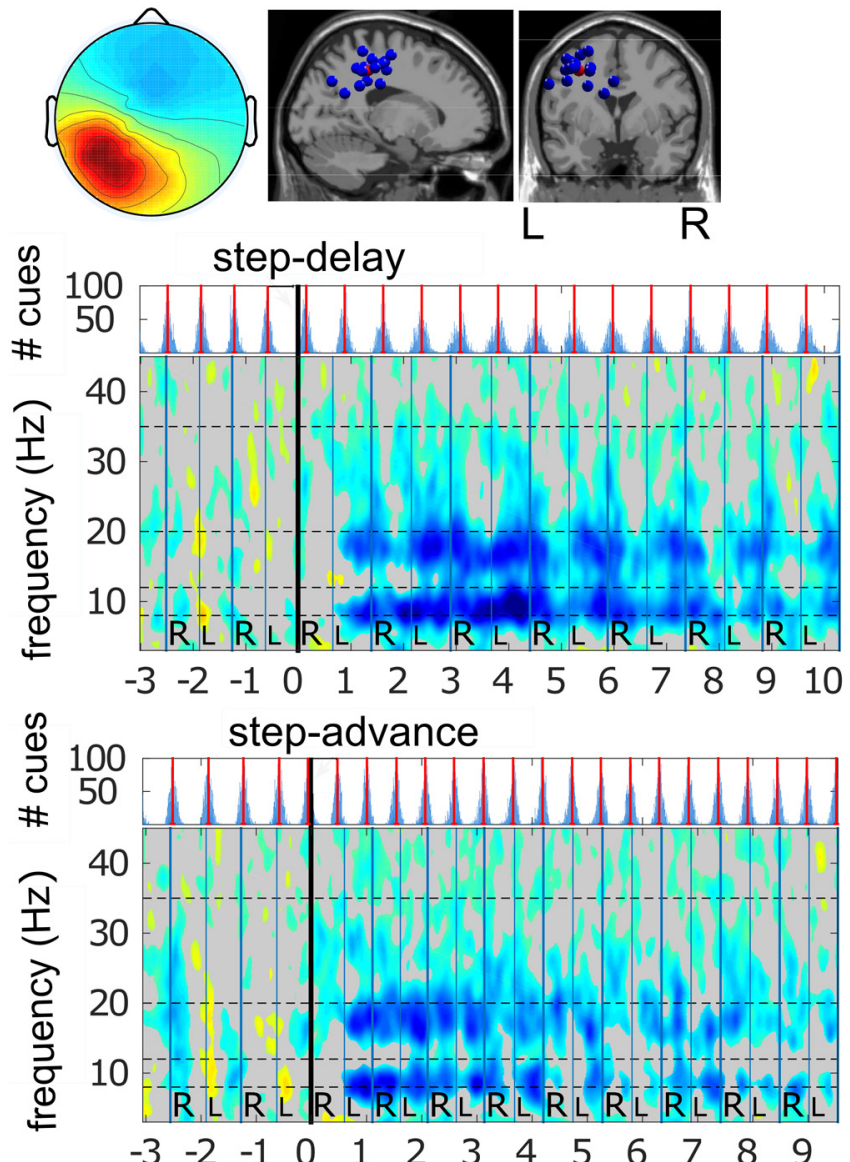

Right parietal cluster (13 Ss, 16 ICs)

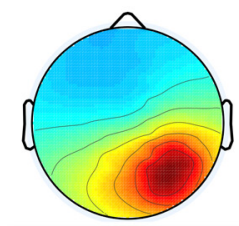

step-delay

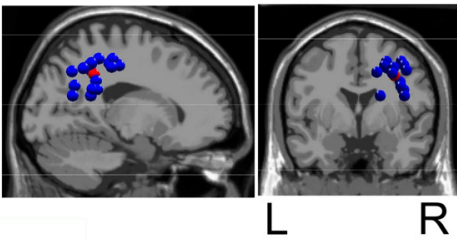

$\mathrm{R}$

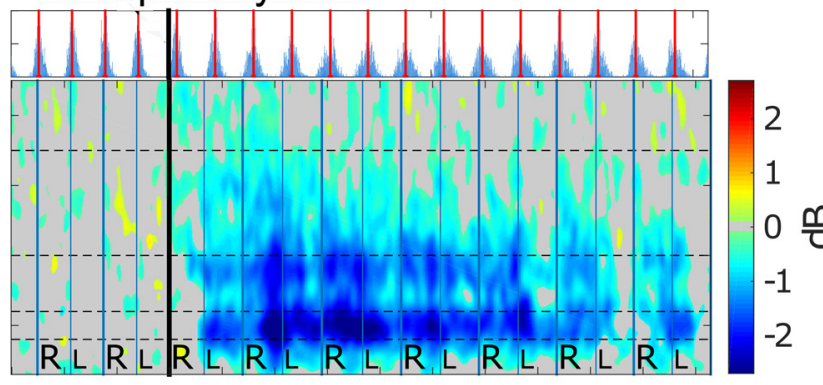

$\begin{array}{llllllllllllll}-3 & -2 & -1 & 0 & 1 & 2 & 3 & 4 & 5 & 6 & 7 & 8 & 9 & 10\end{array}$ step-advance

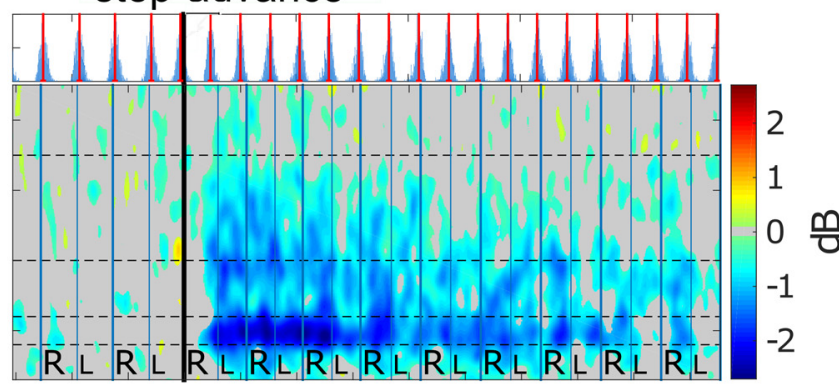

$\begin{array}{lllllllllllll}-3 & -2 & -1 & 0 & 1 & 2 & 3 & 4 & 5 & 6 & 7 & 8 & 9\end{array}$

step latency re tempo shift (s)

Figure 9. Equivalent dipole source locations and cluster-mean scalp projections and ERSP images for IC source clusters in left and right parietal cortex. Cluster-mean ERSP images for step-delay and step-advance conditions were computed and visualized as in Figure 4. Single-trial spectrograms were time warped to median step latencies for heel strikes -7 to 15 before and after tempo shift onsets. ERSP images show long-lasting, shift-induced decreases in $\alpha$ and $\beta$ band power maximal just before heel strikes of the foot contralateral to the cortical location.

Left frontal cluster (13 Ss, 15 ICs)
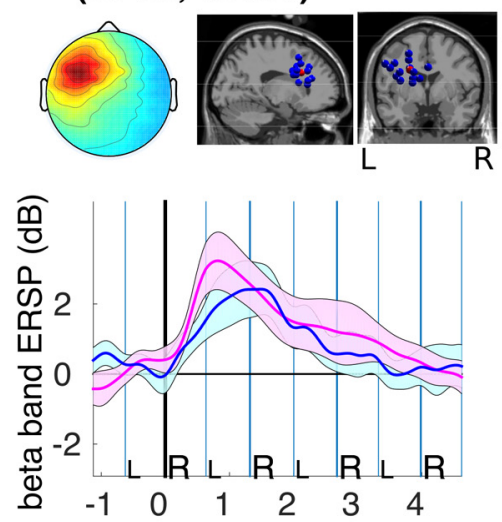

Frontal central cluster (15 Ss, $15 \mathrm{ICs})$

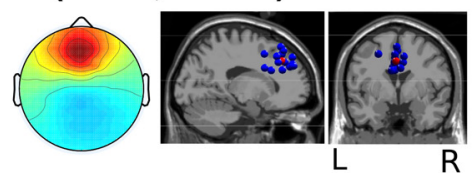

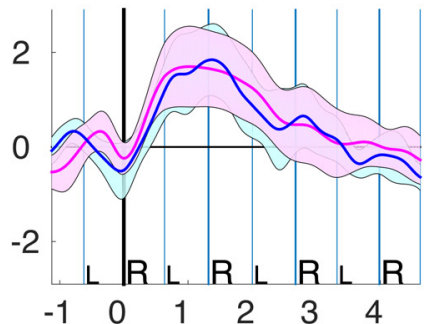

step latency re tempo shift (s)
Right frontal cluster (17 Ss, 19 ICs)
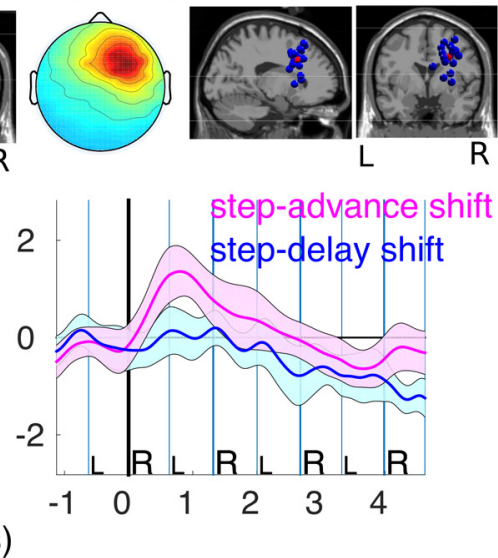

Figure 10. $\quad \beta$-band spectral perturbations in frontal clusters. Individual $\beta$ frequency bands were selected for each individual subject as the frequency within the range $14-20 \mathrm{~Hz}$ having maximal ERSP power variance. For statistical analysis, mean $\beta$-band ERSP time courses time-locked to step-advance and step-delay tempo shifts were computed. Heel strike events were time warped to the same (median) latencies in step-delay and step-advance shift trials. Blue and pink lines and areas represent mean $\beta$ band power as a function of trial latency and its $95 \%$ confidence interval. 0 nly the right frontal cluster shows a significant difference between step advances and step delays (note the nonoverlapping confidence intervals). 
tween step-delay and step-advance trials; this was in the lower $\beta$ band $(14-20 \mathrm{~Hz})\left(F_{(1,18)}=9.67, p=0.006\right)$. This significant difference is highlighted in Figure 10, showing median $\beta$ band ERSP time course and its confidence intervals in step-advance and step-delay shift conditions for each frontal cluster. The difference-ERSP map for the right dorsolateral prefrontal cortex (r-dlPFC) cluster (Fig. 7) also showed a significantly larger increase in $\beta$ band power in step-advance compared with stepdelay trials during the first left and second right foot steps following tempo shifts.

\section{Discussion}

Use of a novel sensorimotor gait synchronization task, coupled with advanced EEG source signal processing methods, revealed two different $\beta$ band oscillatory networks involved in orchestrating motor adjustments during gait adaptation. Our results combined $\mu$ and $\beta$ band power desynchronization (blocking) in motor and parietal cortex (PPC) with a concurrent $\beta$ band power increase in PFC. This indicates two distinct patterns of $\beta$ band activity during gait control: (1) a motor cortical $\mu$ and $\beta$ band decrease expressing motor execution and motor readiness related to gait movements (as in Pfurtscheller and Lopes da Silva, 1999; Neuper et al., 2006; Wagner et al., 2012, 2014; Seeber et al., 2014); and (2) a frontal $\beta$ band increase related to cognitive top-down control (Swann et al., 2009; as in Buschman et al., 2012).

Observed $\mu(7-13 \mathrm{~Hz})$ and $\beta$ band desynchronization (13-30 $\mathrm{Hz})($ Figs. 8, 9) in the motor system after a shift in tempo of the pacing cue sequence may reflect an increased disposition for motor adjustments, as suggested by Engel and Fries (2010), possibly guided by the PFC as proposed by Miller and Cohen (2001; Siegel et al., 2012). The fact that we observed temporary increase in a frontal $\beta$ band oscillatory network (13-20 Hz; Figs. 6, 7, 10) during step tempo adaptation may reflect action monitoring and top-down signaling from PFC to sensorimotor cortex. Our results also show that $\beta$ band power in $\mathrm{r}$-dlPFC was modulated by task difficulty. This lateralized frontal $\beta$ band power increase during step shortening may represent neurocognitive response inhibition processes that actively involve or are accompanied by locally synchronous cortical $\beta$ band oscillations.

\section{Frontal $\beta$ band oscillations in motor control}

Near the second and third heel strikes following shift onsets (Figs. $6,7,10)$, we observed an increase in $\beta$ band power in EEG sources localized to left, central, and right frontal cortex (Table 1). As proposed by Miller and Cohen (2001), these regions may play an important role in the top-down signaling of current behavioral goals to guide adjustment of motor plans. In our task, the participant's goal was to adapt their gait to cue-induced shifts in step tempo involving either a (more difficult) step cue phase advance or an (easier) phase delay. Comparison between decelerations and accelerations revealed significantly higher $\beta$ power in the $\mathrm{r}$-dlPFC during step-advance trials (Figs. 7, 10). This result is in line with our hypothesis and results of the study by Swann et al. (2009) showing a relationship between $\beta$ band $(\sim 16 \mathrm{~Hz})$ power increase in the right inferior frontal gyrus and successful response inhibition in a stop signal task. Because in our task step shortening (in step-advance trials) required inhibiting execution of the accustomed full stride action, it is probable that this process requires more explicit motor inhibition than step lengthening.

Indeed, our behavioral results show that participants performed significantly more accurate step delay (step lengthening) than step advance (step shortening) performance (i.e., they stepped closer in time to the step-delay cues). This is in line with finger tapping studies showing that motor adaptation is somewhat faster to decelerations than to accelerations (Michon, 1967). Our results are the first neurophysiological evidence for previous hypotheses that behavioral preference for longer step adaptation responses in stroke patients (Roerdink et al., 2009) and dual task paradigms (Lovden et al., 2008; Li et al., 2012; De Sanctis et al., 2014) is associated with the higher demands of cognitive control and inhibition involved in step shortening.

Studies have shown that, whereas $\mathrm{r}$-dlPFC is associated with response inhibition (Swann et al., 2009; Aron et al., 2014), medial and left PFC may relate to error detection (Rubia et al., 2003; Ridderinkhof et al., 2004) and to motor adjustment (Miller and Cohen, 2001; Kübler et al., 2006; Cavanagh et al., 2009, 2010; Wittfoth et al., 2009), respectively. This lateral dissociation is in line with our results as only the r-dlPFC source cluster showed a difference between step-advance and step-delay trials, whereas medial and left PFC showed $\beta$ band power increased during both gait accelerations and decelerations.

It has been proposed that frontal cortex interacts with basal ganglia structures during motor suppression and that this interaction occurs via $\beta$ band oscillations (Kühn et al., 2004; Lalo et al., 2008). $\beta$ band synchrony within the basal ganglia-cortical loop promotes tonic activity that is detrimental to voluntary movement, thus providing further evidence for the role of $\beta$ band oscillations in motor inhibition (Jenkinson and Brown, 2011).

The results of our ERP analysis indicate that participants perceived the cue tempo shift after $100 \mathrm{~ms}$ (Fig. 5) and responded to it as early as $250 \mathrm{~ms}$ following the Rcue. In contrast, the $\beta$ band changes we observed began as late as $500 \mathrm{~ms}$ following Rcue and were maintained up to $2000 \mathrm{~ms}$, too late to be related to the pure perception of the cue tempo shift and corresponding to the period when most of the behavioral step adaptation was taking place. Fujioka et al. (2009), for example, showed a $\beta$ band power rebound much earlier (100 ms and lasting up to $450 \mathrm{~ms}$ ) following the omission of a sound from a steady rhythmic sequence. Thus, the frontal $\beta$ band synchronization following Rcue events we observed was not likely related to the simple detection or processing of the cue tempo shift, but likely reflects top-down application of the perceived cue tempo shift to behavioral step adaptation.

\section{Feedback motor control in parietal and central-midline cortices}

The parietal source cluster ERSPs showed a prominent and longlasting decrease in two frequency bands, $\mu(7-12 \mathrm{~Hz})$ and $\beta$ $(18-30 \mathrm{~Hz})$ in (Fig. 9), whereas $\beta$ band power decrease in medial central regions was brief and also involved higher frequencies (up to $35 \mathrm{~Hz}$ ) (Fig. 8). This may suggest that these clusters index different perceptual processes and/or different aspects of gait adaptation. $\mu$ and $\beta$ band power desynchronization in left and right PPC was strongest close in time to contralateral heel strikes during the first up to 17 steps after cue tempo shifts. This may index brain activity involved in the process of matching of heel strikes to auditory cue onsets. Because auditory, visual, and tactile information converges in parietal regions, PPC has been proposed as sensorimotor interface responsible for multisensory integration with ongoing movements (Buneo et al., 2002; Buneo and Andersen, 2006). Thus, PPC may play a key role for anticipatory motor control by sensorimotor feedback matching (Thaut et al., 2008; Krause et al., 2012, 2014).

Krause et al. (2014) have shown that inhibition of the PPC interrupts a matching process of anticipated and real sensorimotor feedback during synchronization but not during continua- 
tion tapping. In a previous study, we showed a decrease in $\mu$ and $\beta$ band power in PPC during visually guided gait adaptation in a virtual environment, suggesting that the PPC is involved in matching steps to visual input (Wagner et al., 2014). Taking into account our current results, the known role of the PPC in mapping visual representations with motor output in space (Buneo and Andersen, 2006) may extend to matching times of occurrence of (expected) auditory and motor events.

Participants performed most adaptation within the first three steps following cue tempo shifts, including a rapid adaptation of step period and beginning a gradual reduction in the phase difference between steps and cues. Finger tapping studies have also shown that a small sudden tempo change in the pacing sequence tends to be followed by rapid adaptation of the tapping period accompanied by slow adaptation of tapping phase (Thaut et al., 1998). Thus, the transient frontal $\beta$ band power increase we observe may index step period adaptation, whereas the longerlasting parietal $\mu$ and $\beta$ band decreases may relate to step phase correction.

\section{$\boldsymbol{\beta}$ band oscillations in temporal prediction}

Interestingly, $\beta$ band activity in both sensory and motor systems seems to reflect anticipatory processes. In the motor system, an upcoming action is reflected in decreased motor cortical $\beta$ band activity that may begin several seconds before execution (Donner et al., 2009), and $\beta$ band corticospinal coherence increases with decreasing likelihood of an upcoming action (Schoffelen et al., 2005). In auditory cortex, violation of top-down expectation (e.g., the omission of a sound from a regular beat sequence) induces a $\beta$ band power increase (Fujioka et al., 2009) that may represent an expectation mismatch response.

Similar to these findings, our results also revealed an $\alpha$ and lower $\beta$ band power $(7-20 \mathrm{~Hz})$ increase in a temporal cortex source cluster following tempo shifts (Fig. 6). Synchronizationcontinuation tapping studies indicate that $\beta$ band power is linked to the development of subjective time and to the guidance of internally driven motor sequences (Bartolo et al., 2014; Bartolo and Merchant, 2015). Precise sensorimotor timing and anticipation of subsequent events are essential to quick adjustment of movements with respect to external changes. Thus, the $\beta$ band activity we observed could point to wider roles of $\beta$ band oscillations in the updating of internal representations for upcoming actions and events (Engel and Fries, 2010; Arnal and Giraud, 2012) to prepare corrective motor adjustments.

\section{Summary and future directions}

In conclusion, our results show two distinct patterns of $\beta$ band oscillatory activity changes following step pacing cue tempo perturbations and suggest that these accompany or subserve motor and cognitive control processes, respectively. To our knowledge, this is the first study to show neural correlates of these two distinct mechanisms acting concurrently in the service of gait adaptation. The size of the $\beta$ band power increase in or near $\mathrm{r}$-dlPFC was modulated according to adaptation difficulty, possibly reflecting engagement of additional movement control resources and providing the first evidence that gait adaptation strategies involving step shortening require more cortical inhibition/control compared with step lengthening. Taking into account our results, deficits in gait adaptation are most probably due to an impairment of prefrontal control guiding motor inhibition. This idea has been previously tested in two TMS studies (del Olmo et al., 2007; Lee et al., 2014). Authors stimulated r-dlPFC using repetitive TMS at $10 \mathrm{~Hz}$ (no other frequencies were tested). Both studies showed improvement in the temporal regularity and pace of gait and tapping, but not of Parkinson symptoms. Our results (along with those of Swann et al., 2009) suggest that stimulation at a higher frequency $(16-17 \mathrm{~Hz})$ might prove more effective. Such interventions might be used for voluntary motor suppression training with real-time feedback of motor cortical $\beta$ oscillations and motor-evoked potentials (as proposed by Majid et al., 2015).

\section{References}

Androulidakis AG, Doyle LM, Yarrow K, Litvak V, Gilbertson TP, Brown P (2007) Anticipatory changes in beta synchrony in the human corticospinal system and associated improvements in task performance. Eur J Neurosci 25:3758-3765. CrossRef Medline

Arnal LH, Giraud AL (2012) Cortical oscillations and sensory predictions. Trends Cogn Sci 16:390-398. CrossRef Medline

Aron AR, Robbins TW, Poldrack RA (2014) Inhibition and the right inferior frontal cortex: one decade on. Trends Cogn Sci 18:177-185. CrossRef Medline

Aschersleben G, Prinz W (1995) Synchronizing actions with events: the role of sensory information. Percept Psychophys 57:305-317. CrossRef Medline

Aschersleben G, Prinz W (1997) Delayed auditory feedback in synchronization. J Mot Behav 29:35-46. CrossRef Medline

Bank PJ, Roerdink M, Peper CE (2011) Comparing the efficacy of metronome beeps and stepping stones to adjust gait: steps to follow! Exp Brain Res 209:159-169. CrossRef Medline

Bartolo R, Prado L, Merchant H (2014) Information processing in the primate basal ganglia during sensory-guided and internally driven rhythmic tapping. J Neurosci 34:3910-3923. CrossRef Medline

Bartolo R, Merchant H (2015) $\beta$ oscillations are linked to the initiation of sensory-cued movement sequences and the internal guidance of regular tapping in the monkey. J Neurosci 35:4635-4640. CrossRef Medline

Bell AJ, Sejnowski TJ (1995) An information-maximization approach to blind separation and blind deconvolution. Neural Comput 7:1129-1159. CrossRef Medline

Benjamini Y, Yekutieli D (2001) The control of the false discovery rate in multiple testing under dependency. Ann Stat 29:1165-1188. CrossRef

Buneo CA, Jarvis MR, Batista AP, Andersen RA (2002) Direct visuomotor transformations for reaching. Nature 416:632-636. CrossRef Medline

Buneo CA, Andersen RA (2006) The posterior parietal cortex: sensorimotor interface for the planning and online control of visually guided movements. Neuropsychologia 44:2594-2606. CrossRef Medline

Buschman TJ, Miller EK (2007) Top-down versus bottom-up control of attention in the prefrontal and posterior parietal cortices. Science 315: 1860-1862. CrossRef Medline

Buschman TJ, Denovellis EL, Diogo C, Bullock D, Miller EK (2012) Synchronous oscillatory neural ensembles for rules in the prefrontal cortex. Neuron 76:838-846. CrossRef Medline

Castermans T, Duvinage M, Cheron G, Dutoit T (2014) About the cortical origin of the low-delta and high-gamma rhythms observed in EEG signals during treadmill walking. Neurosci Lett 561:166-170. CrossRef Medline

Cavanagh JF, Cohen MX, Allen JJ (2009) Prelude to and resolution of an error: EEG phase synchrony reveals cognitive control dynamics during action monitoring. J Neurosci 29:98-105. CrossRef Medline

Cavanagh JF, Frank MJ, Klein TJ, Allen JJ (2010) Frontal theta links prediction errors to behavioral adaptation in reinforcement learning. Neuroimage 49:3198-3209. CrossRef Medline

Cheron G, Duvinage M, De Saedeleer C, Castermans T, Bengoetxea A, Petieau M, Seetharaman K, Hoellinger T, Dan B, Dutoit T, Sylos Labini F, Lacquaniti F, Ivanenko Y (2012) From spinal central pattern generators to cortical network: integrated BCI for walking rehabilitation. Neural Plast 2012:375148. CrossRef Medline

Crone NE, Miglioretti DL, Gordon B, Sieracki JM, Wilson MT, Uematsu S, Lesser RP (1998) Functional mapping of human sensorimotor cortex with electro-corticographic spectral analysis. Brain 121:2271-2299. CrossRef Medline

Debener S, Makeig S, Delorme A, Engel AK (2005) What is novel in the novelty oddball paradigm? Functional significance of the novelty P3 event-related potential as revealed by independent component analysis. Cogn Brain Res 22:309-321. CrossRef Medline 
del Olmo MF, Bello O, Cudeiro J (2007) Transcranial magnetic stimulation over dorsolateral prefrontal cortex in Parkinson's disease. Clin Neurophysiol 118:131-139. CrossRef Medline

Delorme A, Makeig S (2004) EEGLAB: an open source toolbox for analysis of single-trial EEG dynamics including independent component analysis. J Neurosci Methods 134:9-21. CrossRef Medline

Delorme A, Palmer J, Onton J, Oostenveld R, Makeig S (2012) Independent EEG sources are dipolar. PLoS One 7:e30135. CrossRef Medline

Den Otter AR, Geurts AC, de Haart M, Mulder T, Duysens J (2005) Step characteristics during obstacle avoidance in hemiplegic stroke. Exp Brain Res 161:180-192. CrossRef Medline

De Sanctis P, Butler JS, Malcolm BR, Foxe JJ (2014) Recalibration of inhibitory control systems during walking-related dual-task interference: a mobile brain-body imaging (MOBI) study. Neuroimage 94:55-64. CrossRef Medline

Donner TH, Siegel M, Fries P, Engel AK (2009) Build-up of choice predictive activity in human motor cortex during perceptual decision making. Curr Biol 19:1581-1585. CrossRef Medline

Engel AK, Fries P (2010) Beta-band oscillations: signaling the status quo? Curr Opin Neurobiol 20:156-165. CrossRef Medline

Fujioka T, Trainor LJ, Large EW, Ross B (2009) Beta and gamma rhythms in human auditory cortex during musical beat processing. Ann N Y Acad Sci 1169:89-92. CrossRef Medline

Geerligs L, Saliasi E, Maurits NM, Lorist MM (2012) Compensation through increased functional connectivity: neural correlates of inhibition in old and young. J Cogn Neurosci 24:2057-2069. CrossRef Medline

Gilbertson T, Lalo E, Doyle L, Di Lazzaro V, Cioni B, Brown P (2005) Existing motor state is favored at the expense of new movement during $13-35 \mathrm{~Hz}$ oscillatory synchrony in the human corticospinal system. J Neurosci 25:7771-7779. CrossRef Medline

Gola M, Kamiñski J, Brzezicka A, Wróbel A (2012) Beta band oscillations as a correlate of alertness: changes in aging. Int J Psychophysiol 85:62-67. CrossRef Medline

Gola M, Magnuski M, Szumska I, Wróbel A (2013) EEG beta band activity is related to attention and attentional deficits in the visual performance of elderly subjects. Int J Psychophysiol 89:334-341. CrossRef Medline

Gramann K, Gwin JT, Bigdely-Shamlo N, Ferris DP, Makeig S (2010) Visual evoked responses during standing and walking. Front Hum Neurosci 4:202. CrossRef Medline

Gwin JT, Gramann K, Makeig S, Ferris DP (2010) Removal of movement artifact from high-density EEG recorded during walking and running. J Neurophysiol 103:3526-3534. CrossRef Medline

Gwin JT, Gramann K, Makeig S, Ferris DP (2011) Electrocortical activity is coupled to gait cycle phase during treadmill walking. Neuroimage 54: 1289-1296. CrossRef Medline

Haefeli J, Vögeli S, Michel J, DietzV (2011) Preparation and performance of obstacle steps: interaction between brain and spinal neuronal activity. Eur J Neurosci 33:338-348. CrossRef Medline

Hajcak G, Moser JS, Holroyd CB, Simons RF (2006) The feedback-related negativity reflects the binary evaluation of good versus bad outcomes. Biol Psychol 71:148-154. CrossRef Medline

Hofstad CJ, van der Linde H, Nienhuis B, Weerdesteyn V, Duysens J, Geurts AC (2006) High failure rates when avoiding obstacles during treadmill walking in patients with a transtibial amputation. Arch Phys Med Rehabil 87:1115-1122. CrossRef Medline

Holroyd CB, Coles MG (2002) The neural basis of human error processing: reinforcement learning, dopamine, and the error-related negativity. Psychol Rev 109:679-709. CrossRef Medline

Jasper H, Penfield W (1949) Electrocorticograms in man: effect of voluntary movement upon the electrical activity of the precentral gyrus. Arch Psychiatr Nervenkrankheiten 183:163-174. CrossRef

Jenkinson N, Brown P (2011) New insights into the relationship between dopamine, beta oscillations and motor function. Trends Neurosci 34: 611-618. CrossRef Medline

Joundi RA, Jenkinson N, Brittain JS, Aziz TZ, Brown P (2012) Driving oscillatory activity in the human cortex enhances motor performance. Curr Biol 22:403-407. CrossRef Medline

Kline JE, Huang HJ, Snyder KL, Ferris DP (2015) Isolating gait-related movement artifacts in electroencephalography during human walking. J Neural Eng 12:46022. CrossRef Medline

Koenraadt KL, Roelofsen EG, Duysens J, Keijsers NL (2014) Cortical con- trol of normal gait and precision stepping: an fNIRS study. Neuroimage 85:415-422. CrossRef Medline

Krause V, Bashir S, Pollok B, Caipa A, Schnitzler A, Pascual-Leone A (2012) $1 \mathrm{~Hz}$ rTMS of the left posterior parietal cortex (PPC) modifies sensorimotor timing. Neuropsychologia 50:3729-3735. CrossRef Medline

Krause V, Weber J, Pollok B (2014) The posterior parietal cortex (PPC) mediates anticipatory motor control. Brain Stimul 7:800-806. CrossRef Medline

Kübler A, Dixon V, Garavan H (2006) Automaticity and reestablishment of executive control: an fMRI study. J Cogn Neurosci 18:1331-1342. CrossRef Medline

Kühn AA, Williams D, Kupsch A, Limousin P, Hariz M, Schneider GH, Yarrow K, Brown P (2004) Event-related beta desynchronization in human subthalamic nucleus correlates with motor performance. Brain 127: 735-746. CrossRef Medline

Lalo E, Thobois S, Sharott A, Polo G, Mertens P, Pogosyan A, Brown P (2008) Patterns of bidirectional communication between cortex and basal ganglia during movement in patients with Parkinson disease. J Neurosci 28: 3008-3016. CrossRef Medline

Lee TW, Lewicki MS, Girolami M, Sejnowski TJ (1999) Blindsource separation of more sources than mixtures using overcomplete representations. IEEE Signal Processing Lett 6:87-90. CrossRef

Lee SY, Kim MS, Chang WH, Cho JW, Youn JY, Kim YH (2014) Effects of repetitive transcranial magnetic stimulation on freezing of gait in patients with Parkinsonism. Restor Neurol Neurosci 32:743-753. CrossRef Medline

Lewicki MS, Sejnowski TJ (2000) Learning overcomplete representations. Neural Comput 12:337-365. CrossRef Medline

Li KZ, Abbud GA, Fraser SA, DeMont RG (2012) Successful adaptation of gait in healthy older adults during dual-task treadmill walking. Aging Neuropsychol Cogn 19:150-167. CrossRef Medline

Lövdén M, Schaefer S, Pohlmeyer AE, Lindenberger U (2008) Walking variability and working-memory load in aging: a dual-process account relating cognitive control to motor control performance. J Gerontol B Psychol Sci Soc Sci 63:P121-P128. CrossRef Medline

Luck SJ, Kappenman ES (eds) (2011) The Oxford handbook of eventrelated potential components. Oxford: Oxford UP.

Majid DS, Lewis C, Aron AR (2015) Training voluntary motor suppression with real-time feedback of motor evoked potentials. J Neurophysiol 113: 3446-3452. CrossRef Medline

Makeig S (1993) Auditory event-related dynamics of the EEG spectrum and effects of exposure to tones. Electroencephalogr Clin Neurophysiol 86: 283-293. CrossRef Medline

Makeig S, Bell AJ, Jung TP, Sejnowski TJ (1996) Independent component analysis of electroencephalographic data. In: Advances in neural information processing systems (Touretzky D, Mozer M, Hasselmo M, eds), pp 145-151. Cambridge, MA: Massachusetts Institute of Technology.

Makeig S, Jung TP, Bell AJ, Ghahremani D, Sejnowski TJ (1997) Blind separation of auditory event-related brain responses into independent components. Proc Natl Acad Sci U S A 94:10979-10984. CrossRef Medline

Makeig S, Westerfield M, Jung TP, Enghoff S, Townsend J, Courchesne E, Sejnowski TJ (2002) Dynamic brain sources of visual evoked responses. Science 295:690-694. CrossRef Medline

Makeig S, Debener S, Onton J, Delorme A (2004) Mining event-related brain dynamics. Trends Cogn Sci 8:204-210. CrossRef Medline

Makeig S, Gramann K, Jung TP, Sejnowski TJ, Poizner H (2009) Linking brain, mind and behavior. Int J Psychophysiol 73:95-100. CrossRef Medline

Michon JA (1967) Timing in temporal tracking. Soesterberg, The Netherlands: Institute for Perception RVO-TNO.

Miller KJ, Honey CJ, Hermes D, Rao RP, denNijs M,Ojemann JG (2014) Broadband changes in the cortical surface potential track activation of functionally diverse neuronal populations. Neuroimage 85:711-720. CrossRef Medline

Miller R (2007) Theory of the normal waking EEG: from single neurons to waveforms in the alpha, beta and gamma frequency ranges. Int J Psychophysiol 64:18-23. CrossRef Medline

Miller EK, Cohen JD (2001) An integrative theory of prefrontal cortex function. Annu Rev Neurosci 24:167-202. CrossRef Medline

Müller-Putz GR, Zimmermann D, Graimann B, Nestinger K, Korisek G, Pfurtscheller G (2007) Event-related beta EEG-changes during passive 
and attempted foot movements in paraplegic patients. Brain Res 1137: 84-91. CrossRef Medline

Muthukumaraswamy SD (2013) High-frequency brain activity and muscle artifacts in MEG/EEG: a review and recommendations. Front Hum Neurosci 7:138. CrossRef Medline

Neuper C, Wörtz M, Pfurtscheller G (2006) ERD/ERS patterns reflecting sensorimotor activation and deactivation. Prog Brain Res 159:211-222. CrossRef Medline

Onton J, Delorme A, Makeig S (2005) Early visual event-related potential activity in extra-striate cortex. Society for Psychophysiological Research, Lisbon, Sept. 22-25, 2005.

Onton J, Westerfield M, Townsend J, Makeig S (2006) Imaging human EEG dynamics using independent component analysis. Neurosci Biobehav Rev 30:808-822. CrossRef Medline

Onton J, Makeig S (2009) High-frequency broadband modulations of electroencephalographic spectra. Front Hum Neurosci 3:61. CrossRef Medline

Oostenveld R, Oostendorp TF (2002) Validating the boundary element method for forward and inverse EEG computations in the presence of a hole in the skull. Hum Brain Mapp 17:179-192. CrossRef Medline

Palmer JA, Kreutz-Delgado K, Makeig S (2006) Super-Gaussian mixture source model for ICA. In: Lecture notes in computer science (Rosca J, Erdogmus D, Príncipe JC, Haykin S, eds), pp 854-861. Berlin: Springer.

Palmer JA, Makeig S, Kreutz-Delgado K, Rao BD (2008) Newton method for the ICA mixture model. In: IEEE International Conference on Acoustics and Signal Processing, Las Vegas, pp 1805-1808.

Parasuraman R (1980) Effects of information processing demands on slow negative shift latencies and N100 amplitude in selective and divided attention. Biol Psychol 11:217-233. CrossRef Medline

Pelton TA, Johannsen L, Huiya C, Wing AM (2010) Hemiparetic stepping to the beat: asymmetric response to metronome phase shift during treadmill gait. Neurorehabil Neural Repair 24:428-434. CrossRef Medline

Peters M, Durding BM (1979) Footedness of left-and right-handers. Am J Psychol 133-142.

Pfurtscheller G, Berghold A (1989) Patterns of cortical activation during planning of voluntary movement. Electroencephalogr Clin Neurophysiol 72:250-258. CrossRef Medline

Pfurtscheller G, Lopes da Silva FL (1999) Event-related EEG/MEG synchronization and desynchronization: basic principles. Clin Neurophysiol 110: 1842-1857. CrossRef Medline

Pfurtscheller G, Neuper C, Andrew C, Edlinger G (1997) Foot and hand area mu rhythms. Int J Psychophysiol 26:121-135. CrossRef Medline

Pogosyan A, Gaynor LD, Eusebio A, Brown P (2009) Boosting cortical activity at beta-band frequencies slows movement in humans. Curr Biol 19:1637-1641. CrossRef Medline

Repp BH (2001a) Phase correction, phase resetting, and phase shifts after subliminal timing perturbations in sensorimotor synchronization. J Exp Psychol 27:600. CrossRef Medline

Repp BH (2001b) Processes underlying adaptation to tempo changes in sensorimotor synchronization. Hum Mov Sci 20:277-312. CrossRef Medline

Repp BH (2005) Sensorimotor synchronization: a review of the tapping literature. Psychonom Bull Rev 12:969-992. CrossRef Medline

Repp BH, Su YH (2013) Sensorimotor synchronization: a review of recent research (2006-2012). Psychonom Bull Rev 20:403-452. CrossRef Medline

Ridderinkhof KR, Ullsperger M, Crone EA, Nieuwenhuis S (2004) The role of the medial frontal cortex in cognitive control. Science 306:443-447. CrossRef Medline

Roerdink M, Lamoth CJ, Kwakkel G, van Wieringen PC, Beek PJ (2007) Gait coordination after stroke: benefits of acoustically paced treadmill walking. Phys Ther 87:1009-1022. CrossRef Medline

Roerdink M, Lamoth CJ, van Kordelaar J, Elich P, Konijnenbelt M, Kwakkel G, Beek PJ (2009) Rhythm perturbations in acoustically paced treadmill walking after stroke. Neurorehabil Neural Repair 23:668-678. CrossRef Medline

Rubia K, Smith AB, Brammer MJ, Taylor E (2003) Right inferior prefrontal cortex mediates response inhibition while mesial prefrontal cortex is responsible for error detection. Neuroimage 20:351-358. CrossRef Medline

Schoffelen JM, Oostenveld R, Fries P (2005) Neuronal coherence as a mechanism of effective corticospinal interaction. Science 308:111-113. CrossRef Medline

Seeber M, Scherer R, Wagner J, Solis-Escalante T, Müller-Putz GR (2014) EEG beta suppression and low gamma modulation are different elements of human upright walking. Front Hum Neurosci 8:485. CrossRef Medline

Seeber M, Scherer R, Wagner J, Solis-Escalante T, Müller-Putz GR (2015) High and low gamma EEG oscillations in central sensorimotor areas are conversely modulated during the human gait cycle. Neuroimage 112: 318-326. CrossRef Medline

Severens M, Nienhuis B, Desain P, Duysens J (2012) Feasibility of measuring event related desynchronization with electroencephalography during walking. In: IEEE International Conference of Engineering in Medicine and Biology Society, pp 2764-2767. San Diego, CA.

Siegel M, Donner TH, Engel AK (2012) Spectral fingerprints of large-scale neuronal interactions. Nat Rev Neurosci 13:121-134. CrossRef Medline

Snyder KL, Kline JE, Huang HJ, Ferris DP (2015) Independent component analysis of gait-related movement artifact recorded using EEG electrodes during treadmill walking. Front Hum Neurosci 9:639. CrossRef Medline

Solis-Escalante T, Müller-Putz GR, Pfurtscheller G, Neuper C (2012) Cueinduced beta rebound during withholding of overt and covert foot movement. Clin Neurophysiol 123:1182-1190. CrossRef Medline

Suzuki M, Miyai I, Ono T, Oda I, Konishi I, Kochiyama T, Kubota K (2004) Prefrontal and premotor cortices are involved in adapting walking and running speed on the treadmill: an optical imaging study. Neuroimage 23:1020-1026. CrossRef Medline

Swann N, Tandon N, Canolty R, Ellmore TM, McEvoy LK, Dreyer S, DiSano M, Aron AR (2009) Intracranial EEG reveals a time-and frequencyspecific role for the right inferior frontal gyrus and primary motor cortex in stopping initiated responses. J Neurosci 29:12675-12685. CrossRef Medline

Thaut MH, Miller RA, Schauer LM (1998) Multiple synchronization strategies in rhythmic sensorimotor tasks: phase vs period correction. Biol Cybern 79:241-250. CrossRef Medline

Thaut MH, Demartin M, Sanes JN (2008) Brain networks for integrative rhythm formation. PLoS One 3:e2312. CrossRef Medline

Thaut MH, Abiru M (2010) Rhythmic auditory stimulation in rehabilitation of movement disorders: a review of current research. Music Percept 27:263-269. CrossRef

Varraine E, Bonnard M, Pailhous J (2000) Intentional on-line adaptation of stride length in human walking. Exp Brain Res 130:248-257. CrossRef Medline

Wagner J, Solis-Escalante T, Grieshofer P, Neuper C, Müller-Putz G, Scherer R (2012) Level of participation in robotic-assisted treadmill walking modulates midline sensorimotor EEG rhythms in able-bodied subjects. Neuroimage 63:1203-1211. CrossRef Medline

Wagner J, Solis-Escalante T, Scherer R, Neuper C, Müller-Putz G (2014) It's how you get there: walking down a virtual alley activates premotor and parietal areas. Front Hum Neurosci 8:93. CrossRef Medline

Weerdesteyn V, Rijken H, Geurts AC, Smits-Engelsman BC, Mulder T, Duysens J (2006) A five-week exercise program can reduce falls and improve obstacle avoidance in the elderly. Gerontology 52:131-141. CrossRef Medline

Wittfoth M, Schardt DM, Fahle M, Herrmann M (2009) How the brain resolves high conflict situations: double conflict involvement of dorsolateral prefrontal cortex. Neuroimage 44:1201-1209. CrossRef Medline

Zhang Y, Chen Y, Bressler SL, Ding M (2008) Response preparation and inhibition: the role of the cortical sensorimotor beta rhythm. Neuroscience 156:238-246. CrossRef Medline 